Article

\title{
A New Sustainable and Novel Hybrid Solar Chimney Power Plant Design for Power Generation and Seawater Desalination
}

\author{
Emad Abdelsalam ${ }^{1} \oplus$, Fares Almomani ${ }^{2, *}{ }^{\oplus}$, Feras Kafiah ${ }^{1} \oplus$, Eyad Almaitta ${ }^{3}$, Muhammad Tawalbeh ${ }^{4}($, \\ Asma Khasawneh ${ }^{1}{ }^{(0}$, Dareen Habash ${ }^{1}\left[\right.$, Abdullah Omar $^{2}$ and Malek Alkasrawi ${ }^{5}(\mathbb{C}$ \\ 1 School of Engineering Technology, Al Hussein Technical University, Amman 11831, Jordan; \\ emad.abdelsalam@htu.edu.jo (E.A.); feras.kafiah@htu.edu.jo (F.K.); Asma.AlKhasawneh@htu.edu.jo (A.K.); \\ Dareen.Habash@htu.edu.jo (D.H.) \\ 2 Chemical Engineering Department, Qatar University, Doha 2713, Qatar; abdullah.omar@qu.edu.qa \\ 3 Department of Power and Mechatronics Engineering, Tafila Technical University, Tafila 66110, Jordan; \\ e.maita@ttu.edu.jo \\ 4 Sustainable and Renewable Energy Engineering Department (SREE), University of Sharjah, \\ Sharjah P.O. Box 27272, United Arab Emirates; mtawalbeh@sharjah.ac.ae \\ 5 UWSP Paper Science \& Engineering Department, University of Wisconsin, Stevens Point, WI 54481, USA; \\ malkasra@uwsp.edu \\ * Correspondence: falmomani@qu.edu.qa
}

check for updates

Citation: Abdelsalam, E.; Almomani,

F.; Kafiah, F.; Almaitta, E.; Tawalbeh,

M.; Khasawneh, A.; Habash, D.; Omar, A.; Alkasrawi, M. A New Sustainable and Novel Hybrid Solar Chimney Power Plant Design for Power Generation and Seawater Desalination. Sustainability 2021, 13, 12100. https://doi.org/10.3390/ su132112100

Academic Editors: Nuria Novas Castellano and Rosa María García Salvador

Received: 19 September 2021

Accepted: 23 October 2021

Published: 2 November 2021

Publisher's Note: MDPI stays neutral with regard to jurisdictional claims in published maps and institutional affiliations.

Copyright: (c) 2021 by the authors. Licensee MDPI, Basel, Switzerland. This article is an open access article distributed under the terms and conditions of the Creative Commons Attribution (CC BY) license (https:// creativecommons.org/licenses/by/ $4.0 /)$.
Abstract: This study presents a case study of a novel hybrid solar chimney power plant (HSCPP) design's performance in the city of Doha, Qatar. The HSCPP construction is similar to the traditional solar chimney power plant (SCPP) but with the addition of water sprinklers installed at the top of the chimney. This allowed the solar chimney (SC) to operate as a cooling tower (CT) during the nighttime and operate as an SC during the daytime, hence providing a continuous 24-h operation. The results showed that the HSCPP produced $~ 633$ MWh of electrical energy per year, compared to $\sim 380 \mathrm{MWh}$ of energy produced by the traditional SCPP. The results also showed that the HSCPP was able to produce 139,000 tons/year of freshwater, compared to 90,000 tons/year produced by the traditional SCPP. The estimated $\mathrm{CO}_{2}$ emission reduction ( 600 tons/year) from the HSCPP is twice that of the traditional SCPP ( 300 tons/year). The results clearly show that the HSCPP outperformed the traditional SCPP.

Keywords: solar water distillation; solar chimney; cooling tower; hybrid solar chimney

\section{Introduction}

Increasing demand for energy and water, driven by an exponential increase in the world population and industrial growth, without proper management will lead to more stress on the available resources and increased air pollution. The extensive use of fossil fuels plays a major role in air pollution and climate change because of the greenhouse gases (GHG) emitted as a result of using these types of fuels [1-3]. Sustainable, renewable, and clean energy has emerged as a favorable choice to reduce GHG and mitigate climate change impact $[1,4,5]$. Some clean energy technologies, such as solar photovoltaic (PV) and wind, do not depend on water. Many other technologies, however, require huge amounts of water, such as biofuels and nuclear power. This is an additional burden on already scarce water resources. Among all renewable energy technologies, solar PV has increasingly becomes the first utility choice because of its competitive price, but many challenges still lie ahead, such as the efficiency of the PV panel, intermittent nature, and integration policies [6-9]. On the other hand, different solar systems can offer an alternative to solar PV. One of the promising systems that received more attention in recent years is the solar chimney power plant (SCPP) due to its low manufacturing cost and modest design [6-9].

The year 1982 witnessed the construction and successful operation of the first SCPP prototype in Spain [10,11]. There are three distinct units in the SCPP basic model: the 
base-collector, the mechanical rotor, and the chimney. The intercepted solar radiation passes through the base collector and heats the ambient cool air inside the system. The heated air then flows to the entrance of the chimney. The accumulated air at the entrance of the tower leads to a density difference between the air inside and outside the chimney. This density difference creates a pressure gradient that forces the warm air through the chimney. As this air flows, it acts as a driving force on the turbine blades, located at the chimney base, converting the mechanical energy into electrical energy.

Since the first introduction of the Spanish model, several developments have been proposed. Schlaich et al. [12] and Tingzhen et al. [13] investigated the optimization of the dimensional parameters to maximize the electricity output from the SCPP, such as the chimney height, chimney diameter, and collector area. The potential of seawater integration into SCPP to improve process economy and improve efficiency has been proposed in several studies [14-18]. Low thermal efficiency, high levelized cost of energy, large land requirement, and the requirement of a tall chimney are the main challenges that hinder the practical implementation of the SCPP [19-22]. To overcome these challenges, many recent publications have focused on innovative design solutions. These solutions include new design configurations, combined desalination processes with power production, and greenhouse incorporation for crop production [19,23-27]. Table 1 summarizes the literature articles that proposed various modifications of the original SCPP.

Table 1. Literature analysis of certain modifications proposed to boost the efficiency of the SCPP.

\begin{tabular}{cc}
\hline Aim of the Study & Reference(s) \\
\hline Introduce a ventilation system using roof solar chimney & {$[27-31]$} \\
Introduce multi turbo generators and power electronics & {$[29]$} \\
Use different absorber materials and collector types & {$[32-36]$} \\
Improve storing capabilities & {$[37,38]$} \\
Integrate SCPP with PV system & {$[26]$} \\
Insulate the surface of the collector to increase the power & {$[32]$} \\
outcome and the process efficiency & {$[39-41]$} \\
Combine the SCPP with a wind capture device to & \\
harvest wind energy at an elevated height &
\end{tabular}

Many performances and feasibility studies on SCPP across different countries and geographical areas have been conducted to evaluate its potential applications and economic viability. Table 2 presents an overview of the numerical and experimental research contributions based on locations.

Few studies have investigated the possibility of combining CT and SCPP. The prospect of incorporating a cooling tower (CT) with the SCPP has been explored by Zandian and Ashjaee [34] to increase the thermal performance of the power plant. Abdelsalam et al. [35] suggested a novel hybrid SCPP (HSCPP) design that incorporates the traditional SCPP and CT. The new design is based on utilizing the chimney and the bi-directional turbine to extend energy production hours, by operating as a CT at nighttime and as an SCPP during the daytime. The design was validated using weather data in southern Jordan and showed a promising outcome. It is known that the weather data (solar irradiation intensity, temperature, and humidity) is the key operational performance parameter of the SCPP. To provide a solid conclusion of the results reported in our previous work, the HSCPP should be validated in different climate zones. Therefore, the present work aimed to validate the performance of the HSCPP in the Arabian gulf region where the temperature and humidity are the maximum values reached worldwide. This will be the first study that has assessed the performance and economics of the HSCPP in the city of Doha, Qatar, and evaluated the effect of high temperatures and excessive humidity on energy and water production. The study also focused on comparing the performance of the HSCPP in terms of electricity production and freshwater production against a traditional SCPP. Climate benefits related to the reduction in greenhouse gases (GHG) due to the decrease in 
fossil fuel burning for electricity production and the CAPEX and OPEX of the HSCPP are presented and discussed.

Table 2. Studies performed on the use of SCPP for power generation in different geographic locations.

\begin{tabular}{|c|c|c|c|}
\hline Location & Contribution & Year & Reference \\
\hline Saudi Arabia & Numerical study on the performance of SCPP. & 2018 & [36] \\
\hline & Performance analysis of SCPP (power output, levelized & & \\
\hline Nigeria & $\begin{array}{l}\text { cost of electricity (LCOE), and carbon emission } \\
\text { predictions) seven regions. }\end{array}$ & 2017 & [37] \\
\hline Egypt & $\begin{array}{l}\text { Performance assessment of electrical energy via SCPP in } \\
\text { different locations of Egypt theoretically. }\end{array}$ & 2012 & [38] \\
\hline Iran & $\begin{array}{l}\text { Performance evaluation, simulation, and optimization of } \\
\text { different SCPP models in different locations across Iran. }\end{array}$ & $2012,2012,2017,2014$ & [39] \\
\hline Arabian Gulf region & $\begin{array}{l}\text { inside a solar chimney and evaluation of geometric } \\
\text { parameters on power generation. }\end{array}$ & 2011 & [40] \\
\hline Algeria & $\begin{array}{l}\text { Performance and CFD analysis of different SCPP models } \\
\text { across regions in Algeria. }\end{array}$ & $2010,2015,2017$ & [41] \\
\hline Mediterranean region & Analysis and feasibility of implementing solar chimney. & 2008 & [42] \\
\hline Cyprus & A parametric study on the feasibility of solar chimney. & 2014 & [27] \\
\hline China & $\begin{array}{l}\text { Annual performance analysis of the solar chimney power } \\
\text { plant in Sinkiang. Performance analysis of conventional } \\
\text { and sloped solar chimney power plants in China. }\end{array}$ & 2014,2013 & [43] \\
\hline Pacific Island Countries & $\begin{array}{l}\text { Computational and experimental studies on power } \\
\text { generation from SCPP in Pacific Island countries. }\end{array}$ & 2017 & [44] \\
\hline India & Study of economic viability of 200 MW SCPP. & 2014 & [45] \\
\hline
\end{tabular}

\section{Materials and Methods}

\subsection{HSCPP Description}

The design feature of the HSCPP is made up of three modules: a collector, a turbine, and a solar chimney, as presented in Figure 1. In several recent designs [42], the collector contains a seawater basin to saturate the air with water vapor, leading to water desalination when the air leaves the turbine. The structural cross-sectional views of the HSCPP are shown in Figure 1. The design of the HSCPP includes a CT modular function integrated into the SCPP with respect to heat flow but share the energy production via its customized turbines. The CT is integrated with the chimney in a hybrid configuration, offsetting the need for a base structural foundation, as shown in Figure 1b [46]. However, the operational modes of SCPP and CT are separated by synergetic interaction. Moreover, the SCPP is highly dependent on solar radiation, like the PV systems, while the CT is independent of solar radiation and operates at any time. The novel design of the HSCPP offers a unique opportunity to operate over 24 continuous hours for electrical power production and water production. It is worth mentioning that the SCPP and CT operate on the same principle as the air density difference (outside and inside the system boundary). This is the main driving force for power generation. The technical difference between the SCPP and the CT is the heat flow direction of the air entering and leaving the turbines. In the SCPP, the air is heated due to solar radiation increasing its kinetic velocity, whereas the air density (higher humidity) inside the CT is the reason for increasing the air velocity. In the SCPP, the air moves up the chimney and heat flows out to the surrounding area. Meanwhile, the air in the CT moves downward, and the heat flows from the air to the surroundings. According to the ideal gas law, when the air heats up inside the collector, it creates a pressure difference between the bottom and the top of the SCPP. This eventually creates a momentum force that increases the air velocity upward. The upward movement of the air collides with the turbines in a way that is analogous to the wind turbines, leading to electrical power production, as shown in Figure 1a. Similarly, this applies to the CT, but the entering air is cooled down, due to evaporative cooling. To accelerate the cooling effect, the air inside the CT chimney is humidified via a nozzle placed at the top, close to the air entrance. The 
sprayed water via the nozzle creates very tiny water droplets that easily evaporate, due to latent flow from the air. Consequently, the air is cooled and becomes denser. When the water nozzle operates, it increases the air density inside, leading to an increase in pressure, according to the ideal gas law. As a result, the velocity of cold air is increased downwards and collides with the turbine, thereby producing electricity. Interestingly, the futuristic design of the HSCPP is the use of a bi-directional turbine that changes spinning direction (clockwise or counterclockwise), depending on the operational mode of the system as a CT or SCPP. The hybrid design enables the HSCPP to work throughout the day and shifts to the idle mode at night when it is scheduled to work as CT. The novel design lies in its function as a versatile energy system that can operate at any time, depending on the weather condition and the intensity of solar radiation. The most prominent advantage of the design is that it can operate continuously, which increases the utilization efficiency, leading to a decrease in the LCOE.
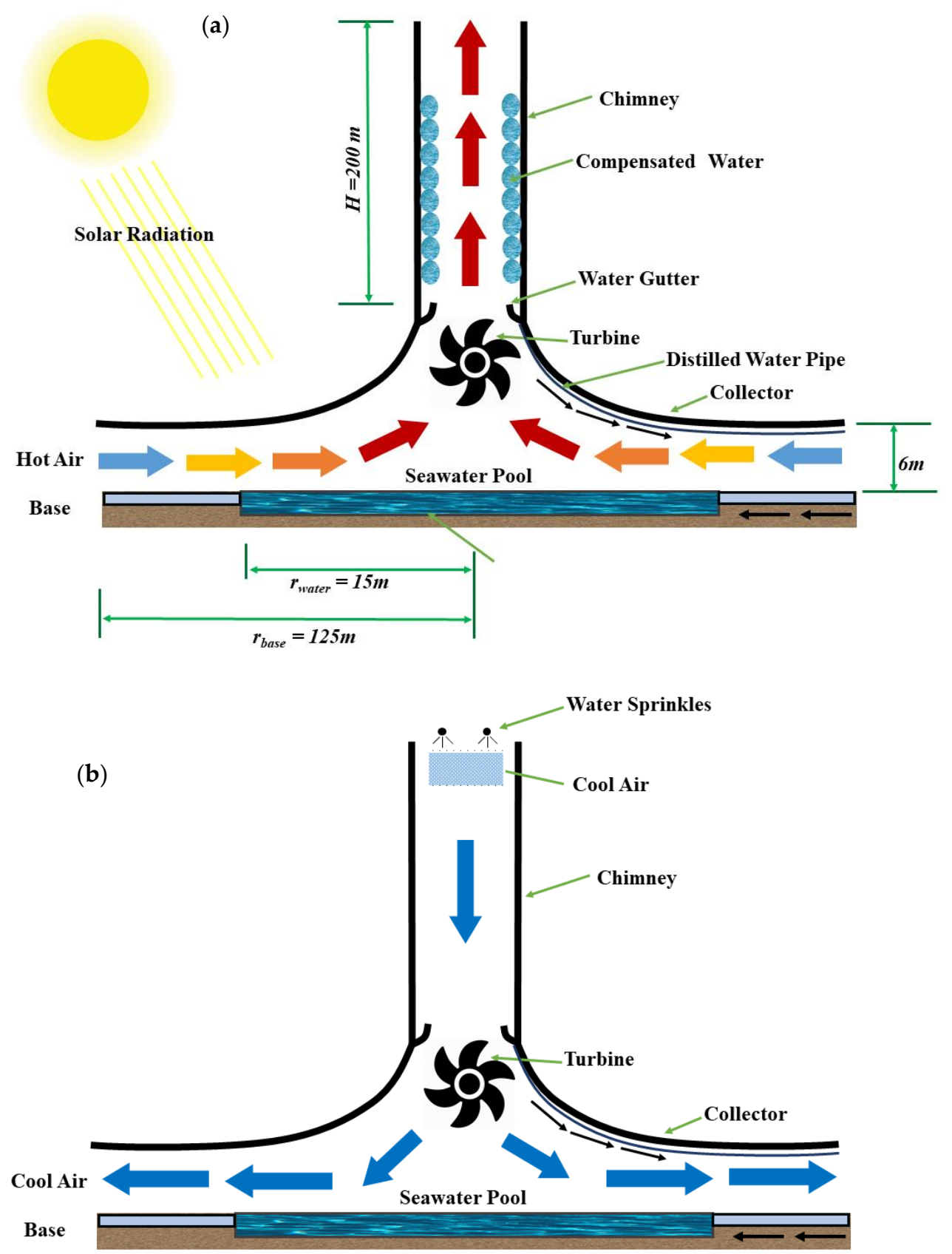

Figure 1. HSCPP system (a) operated as a solar chimney, and (b) operated as a cooling tower. 


\subsection{Mathematical Model}

The novel design was developed mathematically after establishing the mass and energy balance of the HSCPP. The mass and energy balance equations are detailed to describe the system performance from 1 through 11, as shown in Figure 2. The detailed energy balance can be found in the Supplementary Materials. The equations included all the physical properties for both air and water, solved numerically using MATLAB software. The MATLAB program that executed the codes was developed, verified, and tested using the genetic algorithm function built in MATLAB to find the numerical solution for the system operational parameters. The program runs the codes based on initial guessing and continuous iteration until the results do not alter beyond the $1 \times 10^{-6}$. The program code retrieves the weather data, including solar radiation wind velocity, temperature, and relative humidity (RH), from an excel file, and it takes about three hours to handle 1000 data entries. Since we aimed to calculate the power and water production on an annual basis, the program ran for about $26 \mathrm{~h}$ to handle a large amount of data ( 8760 data points). The program used the physical the data of HSCPP, presented in Tables 3 and 4, as a constant input for the numerical analysis.

Table 3. Design parameters of the HSCPP.

\begin{tabular}{cc}
\hline Parameter & Dimension (m) \\
\hline Collector Diameter & 250 \\
Collector Entrance Height & 6 \\
Chimney Height & 200 \\
Chimney Diameter & 10 \\
Depth of Seawater Pool & 0.03 \\
\hline
\end{tabular}

Table 4. Material of construction of the HSCPP and their properties HSCPP.

\begin{tabular}{cccc}
\hline Material & Transmissivity & Emissivity & Absorptivity \\
\hline Glass & 0.90 & 0.90 & 0.05 \\
Water & 0.90 & 0.95 & 0.05 \\
Base & 0.95 & 0.95 & 0.95 \\
\hline
\end{tabular}

The next section shows the main energy balance equations. The detailed equations can be found in the Supplementary Materials.

\subsubsection{Sector 1: Solar Air Heating}

The energy per unit area of the chimney was determined by performing energy balance on the airflow, absorber, and collector as per Equation (1):

$$
q_{c, g l s-a i r}\left(\frac{k w}{m^{2}}\right)+q_{c, a b s-a i r}\left(\frac{k w}{m^{2}}\right)=-\frac{c_{p, a i r}\left(\frac{\mathrm{kJ}}{\mathrm{kg} \cdot \mathrm{K}}\right) \bar{m}_{\text {air }}\left(\frac{\mathrm{kg}}{\mathrm{s}}\right)}{2 \pi r(m)} \frac{d T_{\text {air }(K)}}{d r(m)}
$$

Since the relative humidity is conserved (i.e., $\omega_{1}=\omega_{2}$ ), Equations (2) and (3) can be used to determine the energy in different sections of the structure:

$$
\begin{array}{r}
q_{r, a b s-g l s}\left(\frac{k w}{m^{2}}\right)+q_{c, a b s-a i r}\left(\frac{k w}{m^{2}}\right)+q_{k a b s}\left(\frac{k w}{m^{2}}\right)=\alpha_{a b s} \tau_{g l s} I\left(\frac{k w}{m^{2}}\right) \\
q_{c, g l s-o u t}\left(\frac{k w}{m^{2}}\right)+q_{c, g l s-a i r}\left(\frac{k w}{m^{2}}\right)+q_{r, g l s-s p c}\left(\frac{k w}{m^{2}}\right)=\alpha_{g l s} I\left(\frac{k w}{m^{2}}\right)+q_{r, a b s-g l s}\left(\frac{k w}{m^{2}}\right)
\end{array}
$$




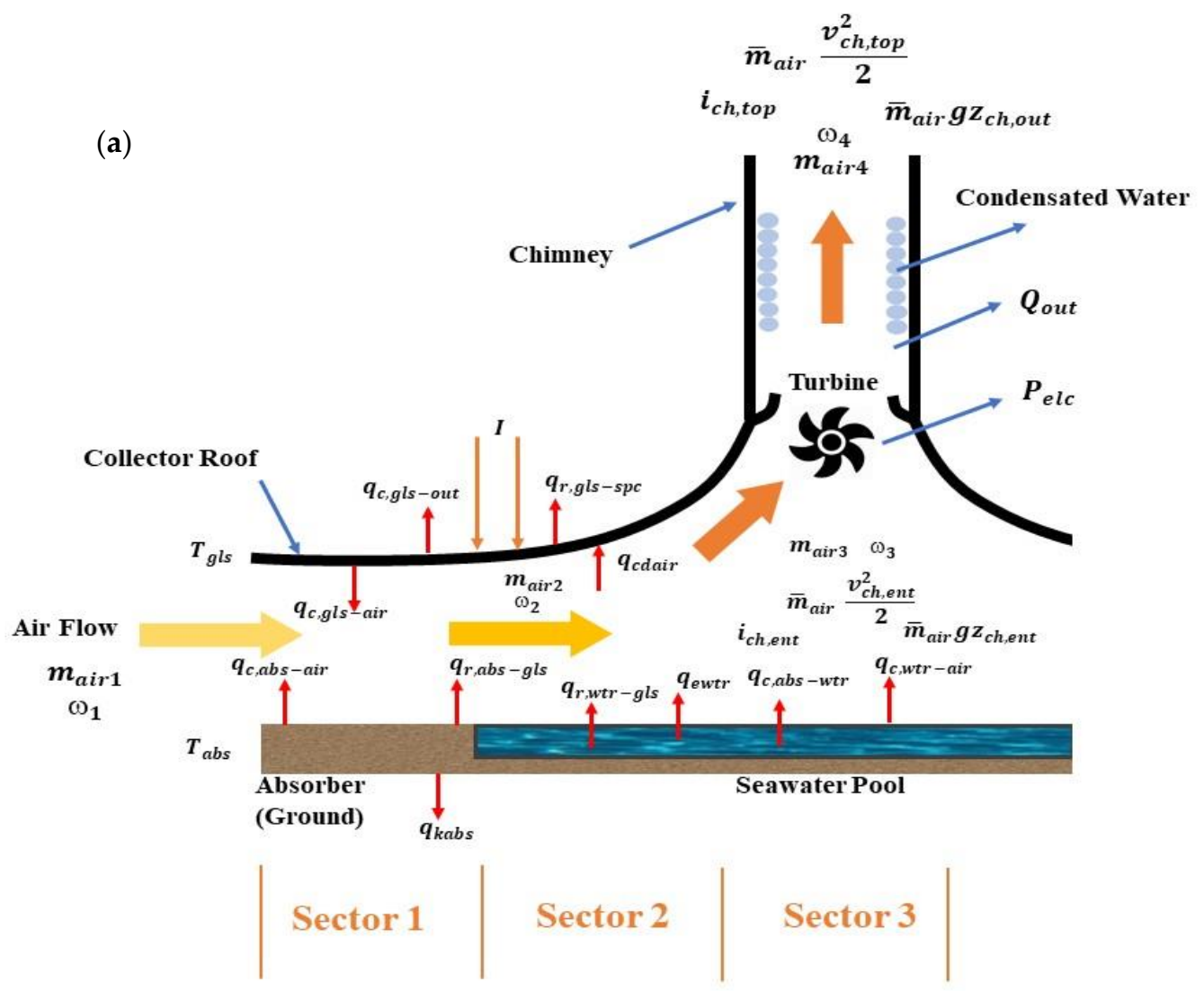

(b)

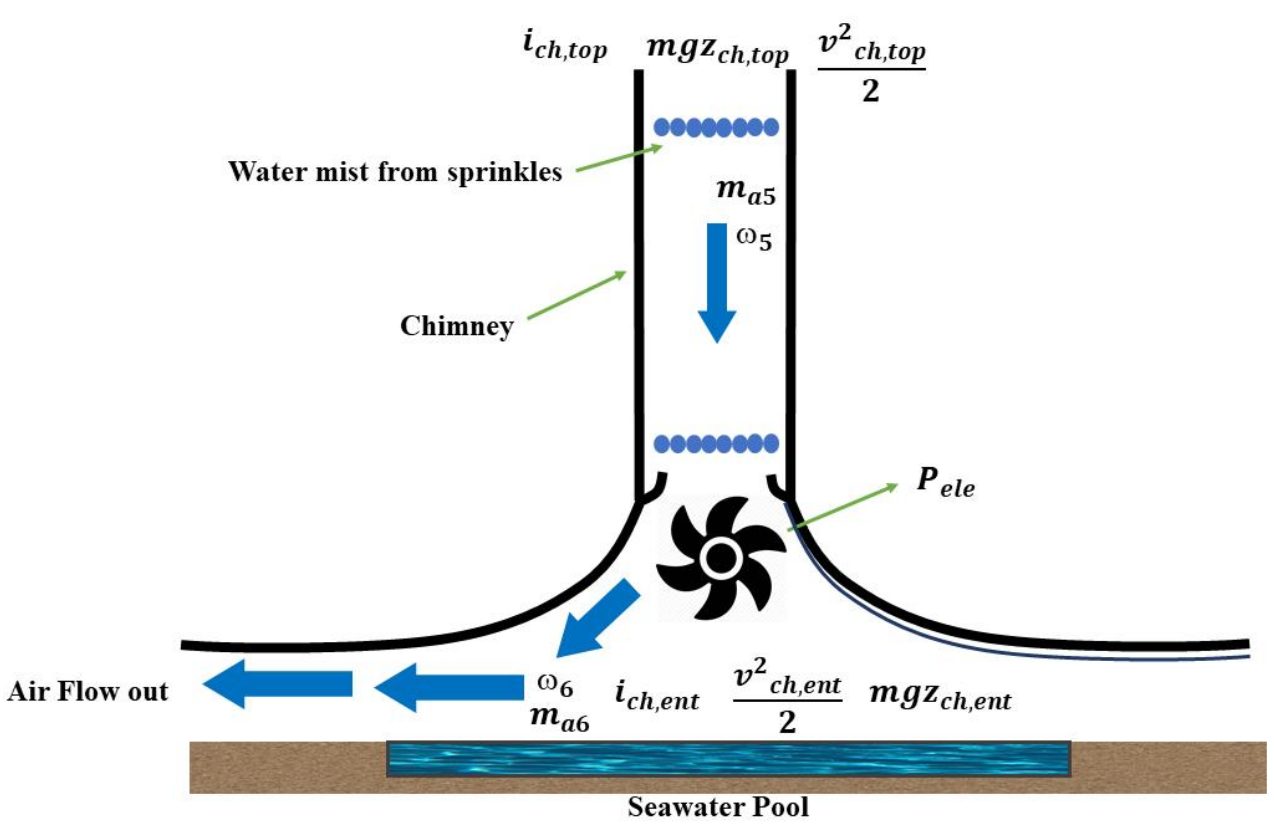

Figure 2. Energy balance across different sections of the HSCPP: (a) sector 1, sector 2, and sector 3; (b) Cooling Tower. 


\subsubsection{Sector 2: Water Evaporation}

The energy balance for the airflow, absorber, and collector per unit area of the seawater pool was applied using Equations (4)-(6):

$$
\begin{array}{r}
q_{c, g l s-a i r}\left(\frac{k w}{m^{2}}\right)+q_{c, w t r-a i r}\left(\frac{k w}{m^{2}}\right)=-\frac{c_{p, a i r}\left(\frac{\mathrm{kJ}}{\mathrm{kg} \cdot \mathrm{K}}\right) \bar{m}_{\text {air }}\left(\frac{k g}{s}\right)}{2 \pi r(m)} \frac{d T_{\text {air }}(K)}{d r(m)} \\
q_{c, a b s-w t r}\left(\frac{k w}{m^{2}}\right)+q_{k a b s}\left(\frac{k w}{m^{2}}\right)=\alpha_{g l s} \tau_{w t r} \tau_{g l s} I\left(\frac{k w}{m^{2}}\right) \\
q_{r, g l s-s p c}\left(\frac{k w}{m^{2}}\right)+q_{c, g l s-o u t}\left(\frac{k w}{m^{2}}\right)=q_{c, g l s-a i r}\left(\frac{k w}{m^{2}}\right)+q_{r, w t r-g l s}\left(\frac{k w}{m^{2}}\right)+\alpha_{g l s} I\left(\frac{k w}{m^{2}}\right)
\end{array}
$$

Similarly, the energy balance of water per unit area of the chimney was calculated following Equation (7):

$$
\begin{gathered}
q_{e w t r}\left(\frac{k w}{m^{2}}\right)+q_{r, w t r-a i r}\left(\frac{k w}{m^{2}}\right)+q_{c, w t r-a i r}\left(\frac{k w}{m^{2}}\right)+\frac{c_{p, w t r}\left(\frac{\mathrm{kJ}}{\mathrm{kg} . \mathrm{K}}\right) \bar{m}_{w t r}\left(\frac{k g}{s}\right)}{2 \pi r(m)} \frac{d T_{w w r}(k)}{d r(m)} \\
=q_{c, a b s-w t r}\left(\frac{k w}{m^{2}}\right)+\alpha_{w t r} \tau_{g l s} I\left(\frac{k w}{m^{2}}\right)
\end{gathered}
$$

The velocity of the air entering the chimney was calculated using the Bernoulli equation within the chimney following Equation (8) [47]:

$$
V_{c h}\left(\frac{m}{s}\right)=\sqrt{2 g\left(\frac{m}{s^{2}}\right) H_{\text {ch }}(m) \frac{T_{\text {ch, ent }}-T_{\text {out }}}{T_{\text {out }}}}
$$

The output power of the turbine was determined using Equation (9) [48]:

$$
P_{\text {elc }}(\mathrm{w})=\frac{1}{2} \rho_{e n, c h}\left(\frac{\mathrm{kg}}{\mathrm{m}^{3}}\right) C_{f} A_{c h}\left(m^{2}\right) V_{c h}^{3}\left(\frac{\mathrm{m}^{3}}{\mathrm{~s}^{3}}\right)
$$

where, $C_{f}$ is the turbine efficiency, 0.42 .

\subsubsection{Sector 3: Chimney}

During the daytime, the HSCPP operates as an SCPP; hence, the energy balance equations are:

$$
\begin{aligned}
P_{\text {elc }}(\mathrm{kw})+Q_{\text {out }}(\mathrm{kw})= & \bar{m}_{\text {air }}\left(\frac{\mathrm{kg}}{s}\right)\left[\left(\frac{v_{\text {ch,ent }}^{2}}{2}\left(\frac{m^{2}}{s^{2}}\right)+g z_{\text {ch,ent }}\left(\frac{m^{2}}{s^{2}}\right)+i_{\text {ch,ent }}\left(\frac{m^{2}}{s^{2}}\right)\right)\right. \\
& \left.-\left(\frac{v_{\text {ch,out }}^{2}}{2}+g z_{\text {ch,out }}+i_{\text {ch,out }}\right)\right]
\end{aligned}
$$

The utilization factor for electricity production was calculated as follows:

$$
\eta=\frac{P_{e l c}}{\frac{1}{4} \pi\left(D_{c o l}^{2}-D_{c h}^{2}\right) I}
$$

\subsection{Model Validation}

The established HSCCP model was validated against the outcomes reported by Zuo et al. [47]. The temperature profile (from the entrance of the collector to the beginning of the chimney) of the developed HSCPP was in excellent agreement with the values reported by Zuo et al. [47]. The temperature profiles values were compared using one-way analysis of variance (ANOVA) at a significance level of $5 \%$, where the determination coefficient $\left(R^{2}\right)$, 
Equation (12), the root mean square (RMS) Equation (13), and difference residuals were used to judge the difference between the data sets:

$$
\begin{gathered}
R^{2}=1-\frac{\sum_{i=1}^{m}\left(T_{c a l}-T_{r e f}\right)^{2}}{\sum_{i=11}^{m}\left(T_{\text {lit }}-\bar{T}_{r e f}\right)^{2}} \\
\text { RMS }=\sqrt{\frac{\sum T_{c a l}-T_{r e f}}{N \sum T_{c a l}^{2}}}
\end{gathered}
$$

where $T_{\text {cal }}$ is the calculated temperature and $T_{\text {ref }}$ is the referenced values from Zuo et al. [47]. The $R^{2}$ and RMS of the results were found to be $0.66 \%$ and $0.98 \%$, respectively, confirming that the developed model can predict the temperature profile of both HSCPP and SCCP. The low range of residuals between the calculated and referenced temperature profile specifies that there is very small variation between both values and confirms the ability of the used model to represent the SCCP without any significant systematic errors. Figure 3 indicates that the air temperature rises as a function of the radial distance, where the maximum temperature was located at the lower end of the chimney. This significant $\Delta T$ represents the main design parameter that develops the air mass flow within the system and contributes to energy production, as will be discussed later.

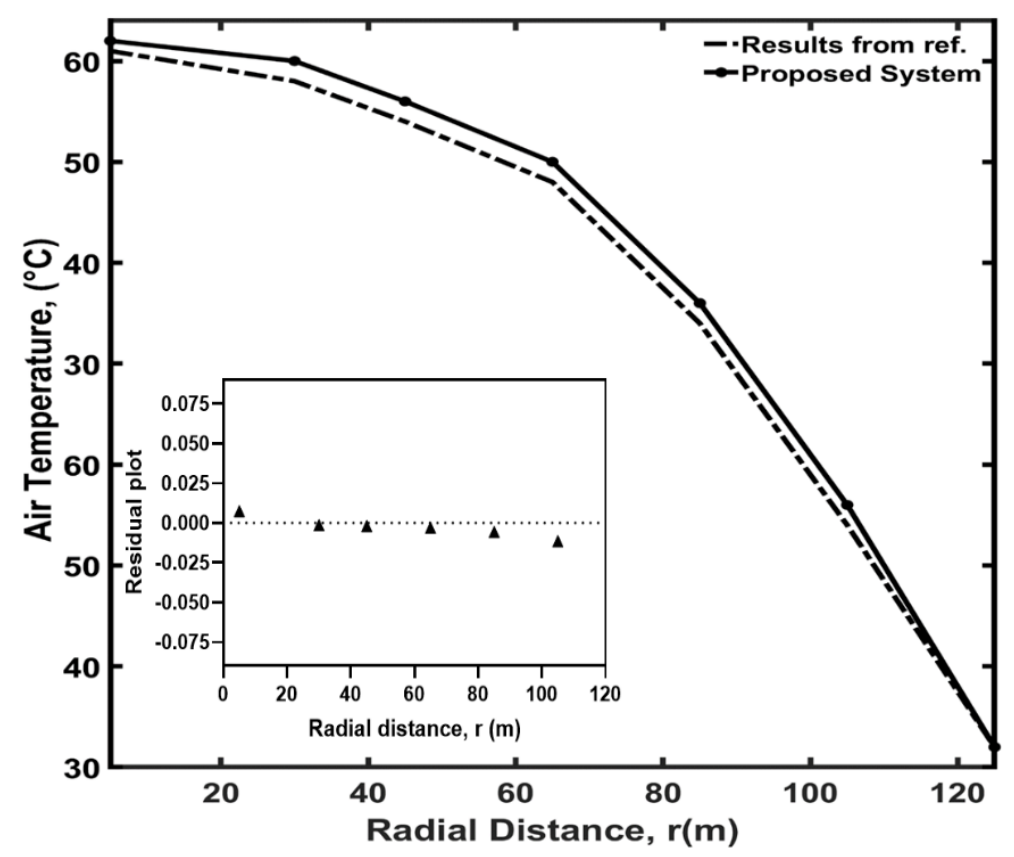

Figure 3. Mathematical model of the HSCPP validation against the temperature profile obtained by Zuo et al. [47].

\subsection{Cost Analysis}

The cost analysis of the SCPP includes fixed capital costs, operating costs, and revenues. The fixed capital cost calculation was based on the historical method adjusted to the production capacity (i.e., online published information related to the process construction cost at similar capacities). The detailed procedure for the cost analysis can be found in our previous work [35]. The operating cost, which includes maintenance, labor, insurance, license, and taxes, was estimated as a function of the fixed capital investment. It was assumed that in the first period of the plant (up to year 9), it is around $4 \%$ of the yearly capital, it increases to $5 \%$ from year 10 to 17 , and then increases again to 6.5 after 17 years. The revenue was judged based on the payback time, return on investment (ROI), which 
represents the percentage ratio of annual profit to the capital investment, and discounted cash flow rate of return (DCFRR).

\section{Results and Discussion}

Figure 4 presents an example of a weather data profile (solar irradiance, ambient temperature, wind speed, and RH) obtained from Doha, Qatar $\left(25.2854^{\circ} \mathrm{N}, 51.5310^{\circ} \mathrm{E}\right)$ in different seasons. The general trends show that solar irradiance is at its lowest when the sunlight is weak (i.e., during the early period of the day and at night). The daily solar irradiance was estimated to be in the range of 287 to $857 \mathrm{~W} / \mathrm{m}^{2}$, with a maximum value of $849 \pm 8 \mathrm{~W} / \mathrm{m}^{2}$ achieved in the period from 9:00 am to 12:00 midday. The average daily solar irradiation was estimated to be $334.1 \mathrm{~W} / \mathrm{m}^{2}$. The temperature profile in Doha shows a slight fluctuation between day and night. Figure 4 show that the temperature ranged from 16.0 to $27.0^{\circ} \mathrm{C}, 12.0$ to $41.5^{\circ} \mathrm{C}, 12.0$ to $47.5^{\circ} \mathrm{C}$, and 30.0 to $36.0^{\circ} \mathrm{C}$, in January, May, August, and October with average values of $20.8,23.9,29.2$, and $29.9^{\circ} \mathrm{C}$, respectively. A temperature peak of $42.3^{\circ} \mathrm{C}$ was usually observed at noon. The $\mathrm{RH}$ is observably inversely proportional to the temperature. A maximum of $67 \%$ was reported at night and a daily average value of $50 \%$, dropping to $20 \%$ during the hottest and driest period of the day. The wind speed was recorded to be in the range of $1.5-6.7 \mathrm{~m} / \mathrm{s}$ with an average value of 3.7 $\mathrm{m} / \mathrm{s}$, although this change will be shown in the following sections to have a minimum impact on the performance of the SCCP, as opposed to the other factors. By using solar irradiation during the day and acting as a CT during the night, the proposed design would take advantage of the weather data profile and thereby contribute to 24-h energy output.

Figure 5a summarizes the monthly minimum, maximum, and average solar irradiance records across the year. The solar irradiations are at the maximum level in the summer months (June to September) with a maximum observed in June $\left(7800 \mathrm{~W} / \mathrm{m}^{2}\right)$, and it drops to lower values starting from October, reaching the minimum value at the end of the year (see Figure $4 \mathrm{a}-\mathrm{d}$ ). It is worth noting that there is a big difference between the minimum and maximum irradiation profiles. While the maximum irradiation profile values fluctuate relatively insignificantly and take a uniform parabolic shape, the minimum value seems to wildly differ from month to month. It is believed that the uniform maximum irradiation profile is due to insignificant differences between the hottest and coldest months. The maximum solar irradiation is usually reported in the time period 10:00 am to 1:00 pm all year round. At this time, Doha, the studied area, is characterized by a clear sky and sunny time. Therefore, the reported maximum solar irradiation is almost uniform, i.e., the shift in monthly solar energy received is caused by a slight change in the maximum reported irradiation values. Meanwhile, the minimum solar irradiation values seem to wildly differ from month to month, with a staggering near the low value of $150 \mathrm{~W} / \mathrm{m}^{2}$ during March and December, and a surprise increase in the maximum value in June. This would suggest another important piece of information for solar power-based technology: the difference in solar radiation between the cool day periods and hot ones during extremely hot summer months is marginal compared to that during the beginning and end of the year, highlighting the extra advantage gained from operating the plant all year round rather than only during the summer (i.e., there is an advantage brought by operating the plant during both hot and cold months). This intense solar irradiation represents promising renewable energy to generate electricity and water using the proposed HSCPP. The reported solar irradiance results are promising when compared to other existing established SCPP, such as that of Hamdan [40], who calculated that a solar chimney could produce up to $50 \mathrm{MW}$ with solar irradiation of $263 \mathrm{~W} / \mathrm{m}^{2}$, though the physical specifications of the SCCP (collector radius $\sim 1000 \mathrm{~m}$, chimney radius $\sim 50 \mathrm{~m}$, and chimney height $\sim 1000 \mathrm{~m}$ ) are different from the one proposed in the present study. Additionally, Larbi et al. [48] investigated and proved the feasibility of the SCPP that was operated with an average daily and working hour solar irradiance of 229 and $611 \mathrm{~W} / \mathrm{m}^{2}$, producing 140-200 kW, which was sufficient for the needs of remote villages in southwestern Algeria. 

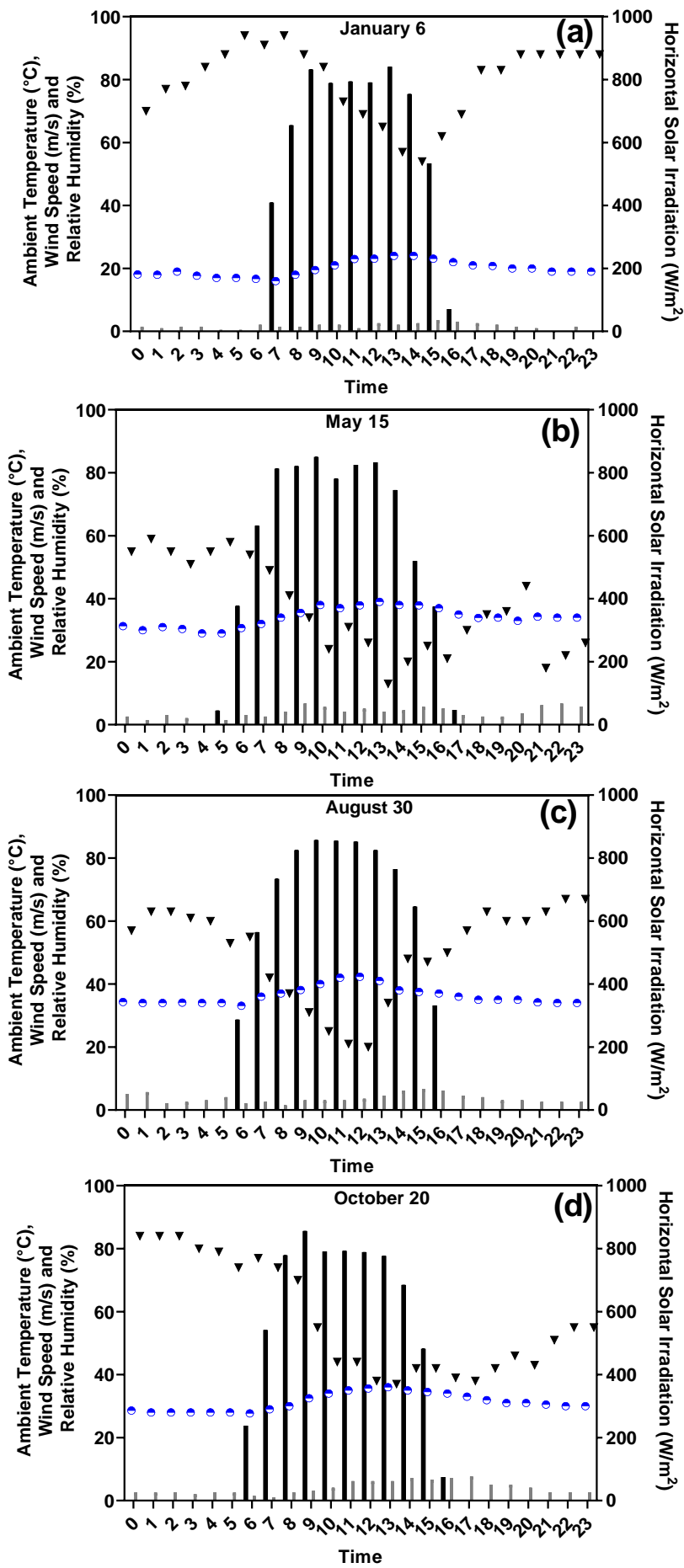

\section{- Solar Irradiation}

$\odot$ Ambient Temperature
Wind Speed

$\checkmark$ Relative Humidity

Figure 4. Daily weather data at Doha, Qatar (a) 6 January, (b) 15 May, (c) 30 August, and (d) 20 October

\subsection{SCPP Performance}

Figure $5 \mathrm{~b}$ shows the monthly minimum, maximum, and average power generation for the HSCPP. It can be seen that it follows the same trend as solar radiation, and this is because solar irradiation is the main key operational parameter used to develop the temperature gradient $(\Delta T)$ within the HSCPP, which is considered the main reason for 
the airflow and consequently the energy production. As the solar irradiation intensity increases, the absorbed energy by the HSCCP increases, leading to the development of high $\Delta T$ between the inlet and outlet of the system. This $\Delta T$ will create a pressure difference between hot and cold air and thus increase the airflow in the structure and produce energy by operating the turbine. Therefore, the direct proportional relation between the solar irradiation and power generation trends makes sense. The average monthly energy production from the HSCPP ranged from $900-1150 \mathrm{kWh}$, with the maximum reported in the range of 1150-1300 $\mathrm{kWh}$, with the hotter mid-year months (May to June) being more promising in terms of energy production. Since the power produced from the HSCPP follows the same trend as the received solar radiation from the sun across the year, the two implications discussed earlier regarding irradiance variation and comparison between the minimum and maximum values also apply here as well. The observed trend can also be used to correlate the expected energy production in different regions, with the climate conditions in general and solar irradiation specifically. The variation in the maximum energy output across the year is relatively small, compared to the spikes in minimum values, and the difference between the minimum and maximum energy output during the hottest months is relatively small.

Table 5 provides a summary of the power generation from SCPP in different countries, different SCPP design parameters, and different climate conditions. It can be seen that the annual power generation from the HSCPP in Qatar is higher than the values reported in the literature for different countries, except for the study reported by Guo et al. [43], Akhtar and Rao [45], and Okoye et al. [27] due to the big difference in the collector diameter proposed in these studies, which is difficult and expensive to construct. In addition, the cumulative annual electricity production reported in the present study is 2.5 to 3 times higher than the classical SCPP (377 MWh) as reported by Zuo et al. [47], and 1.9-2.3 orders of magnitude higher than hybrid solar chimney power plant (528 MWh) reported by Abdelsalam et al. [35]. Besides, the power generation reported in this study is significantly higher than the values reported in the literature under similar climate conditions. Tingzhem et al. [13] produced no more than $35 \mathrm{~kW}$ for SCPP operated under a solar radiation intensity of $800 \mathrm{~W} / \mathrm{m}^{2}$. Larbi et al. [41] produced electricity in the range of 140 and $200 \mathrm{~kW}$ with the solar irradiation and ambient temperature in the range of 400 to $600 \mathrm{~W} / \mathrm{m}^{2}$ and 20 to $38^{\circ} \mathrm{C}$, respectively. Abdelmohimen et al. [36] reported a numerical performance for an SCPP in the range of $55-63 \mathrm{~kW}$ for solar irradiation in the range $715-765 \mathrm{~W} / \mathrm{m}^{2}$.

(a)



Figure 5. Cont. 
(b)

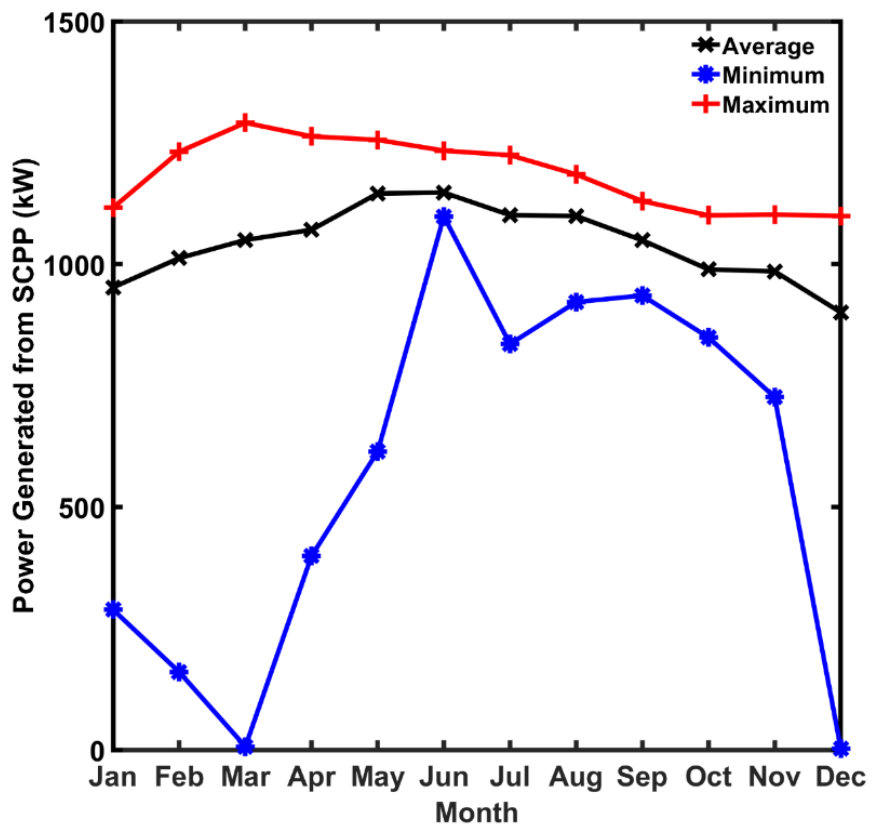

(c)

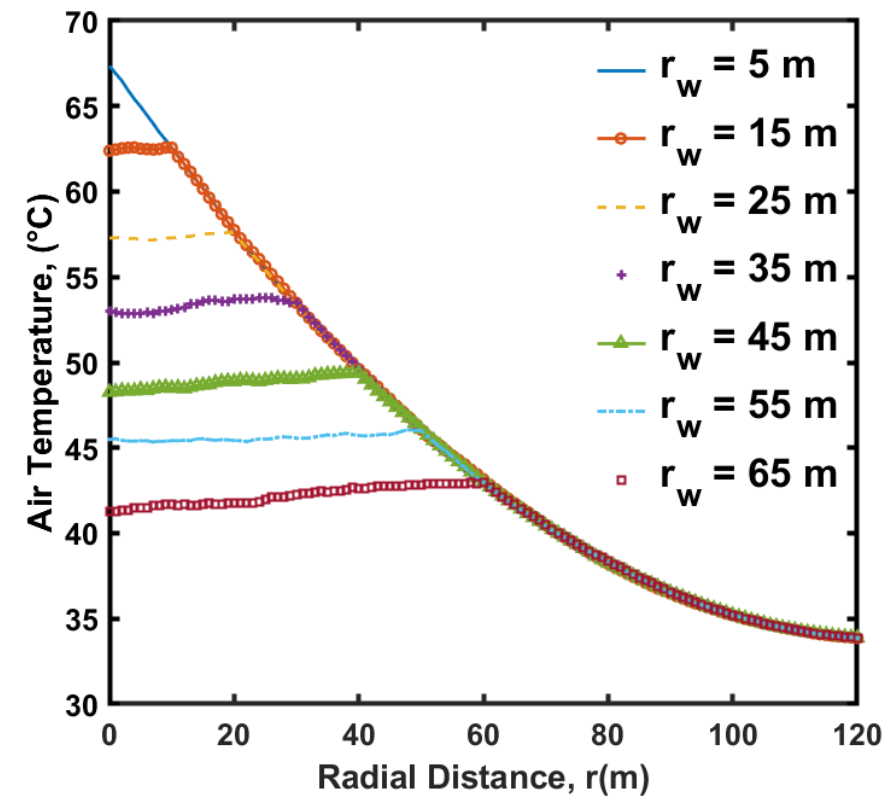

Figure 5. (a) Monthly minimum, maximum, and average solar irradiance record across the year at Doha, Qatar; (b) monthly minimum, maximum, and average power generation for the HSCPP; and (c) the variation of air temperature as a function of the radius of the water pool radius in the HSCPP. 
Table 5. Summary of the power generation from SCPP in different countries, different SCPP design parameters, and different climate conditions.

\begin{tabular}{|c|c|c|c|c|}
\hline Location & $\begin{array}{c}\text { Annual Energy } \\
\text { Production (kWh) }\end{array}$ & $\begin{array}{c}\text { Daily Solar } \\
\text { Irradiance Range } \\
\left(\mathrm{W} / \mathrm{m}^{2}\right)\end{array}$ & Design Parameters & Reference \\
\hline Saudi Arabia & $660-765$ & $715-765$ & $\begin{array}{l}\text { H: } 195 \mathrm{~m}, \mathrm{~h}: 2 \mathrm{~m} \\
\text { D: } 244 \mathrm{~m}, \mathrm{~d}: 10 \mathrm{~m}\end{array}$ & [36] \\
\hline Nigeria & $602-738$ & $840-860$ & $\begin{array}{l}\text { H: } 150 \mathrm{~m}, \mathrm{~h}: 2.5 \mathrm{~m} \\
\text { D: } 600 \mathrm{~m}, \mathrm{~d}: 10 \mathrm{~m}\end{array}$ & [37] \\
\hline Egypt & $1.6-1.7 \times 10^{5}$ & $500-950$ & H: 500 m, D: 3000 m, d: 50 m & [38] \\
\hline Iran & 13,000 to 26,000 & $450-750$ & H: 350 m, D: 1000 m, & [39] \\
\hline Iran & $120,000-336,000$ * & $450-750$ & $\begin{array}{l}\text { H: } 200 \mathrm{~m}, \mathrm{~h}: 2 \mathrm{~m} \\
\text { D: } 244 \mathrm{~m}, \mathrm{~d}: 10 \mathrm{~m} \text {, }\end{array}$ & [49] \\
\hline $\begin{array}{l}\text { Arabian Gulf } \\
\text { region }\end{array}$ & $+104,000$ & $185-1250$ & H: 500 m, D: 1000 m & [40] \\
\hline Algeria & $700-720$ & $420-620$ & $\begin{array}{l}\text { H: } 200 \mathrm{~m}, \mathrm{~h}: 2.5 \mathrm{~m} \\
\text { D: } 500 \mathrm{~m}, \mathrm{~d}: 10 \mathrm{~m},\end{array}$ & [41] \\
\hline $\begin{array}{l}\text { Mediterranean } \\
\text { region }\end{array}$ & $5000-6200 *$ & $130-750$ & $\begin{array}{c}\text { H: } 550 \mathrm{~m}, \\
\text { D: } 1250 \mathrm{~m}, \mathrm{~d}: 82 \mathrm{~m}\end{array}$ & [42] \\
\hline Cyprus & 945,000 & $120-700$ & $\begin{array}{l}\text { H: } 750 \text { m, h: } 2.5 \mathrm{~m} \\
\text { D: } 2900 \text { m, d: } 70 \mathrm{~m}\end{array}$ & [27] \\
\hline China & $1,300,000$ * & 200-1000 & $\begin{array}{c}\text { H: } 1000 \mathrm{~m}, \\
\mathrm{D}: 2750 \mathrm{~m}, \mathrm{~d}: 120 \mathrm{~m},\end{array}$ & [43] \\
\hline $\begin{array}{l}\text { Pacific Island } \\
\text { Countries }\end{array}$ & 560 & 608 & $\begin{array}{l}\text { H: } 100 \mathrm{~m}, \mathrm{~h}: 0.5 \mathrm{~m} \\
\text { D: } 80 \mathrm{~m} \text {, d: } 2.5 \mathrm{~m}\end{array}$ & [44] \\
\hline India & $2,600,000 *$ & & - & [45] \\
\hline Qatar & $633,125.9$ & 125 to 850 & $\begin{array}{l}\text { H: } 200 \mathrm{~m}, \mathrm{~h}: 6 \mathrm{~m}, \\
\text { D: } 250 \mathrm{~m}, \mathrm{~d}: 10 \mathrm{~m}\end{array}$ & This study \\
\hline
\end{tabular}

H: Chimney height, h: Collector inlet height, D: Collector diameter; $\mathrm{d}$ : Chimney diameter. ${ }^{*}$ corrected to $15 \mathrm{~h}$ solar irradiation/day.

The principal explanation for the substantial output of electrical power is the arrangement of the HSCPP. The system was operated as SCPP and CT in parallel, contributing to the combined production of electricity. The intercepted solar irradiation was used throughout the day to heat the air under the collector. The heat absorbed increases the temperature of the air, reduces its density, and induces a streamlined velocity over the seawater pool. The airflow pushes the hot air up the chimney to allow the ambient outside temperature to reach the chimney and maintain continuous airflow. The heat absorbed also evaporates part of the water, leading to an improvement in the air's percent $\mathrm{RH}$ and improving the cooling effect. The difference in temperature and pressure between the inside and outside of the chimney pushes hot air through the chimney, where the kinetic energy is converted to mechanical energy, thereby producing electricity.

The effect of the water pool radius on the air temperature within the HSCCP is another important operational parameter because this value determines the magnitude of the distilled water production and electric power generation. Figure $5 c$ shows the temperature profile of the air entering the chimney from the collector entrance under different values of the pool radius. Generally speaking, the air temperature increases as it travels towards the chimney entrance due to the contact between the air and solar glass heating. However, once the air reaches the water pool zone, water evaporates into the air, saturating it and decreasing its temperature. So, while the net change in air temperature is still positive due to the dominant effect of solar heating, the surface area of the water pool (radius) has a significant effect on the chimney inlet air temperature. A lower pool surface area implies a smaller decrease in air temperature and consequently lower distilled water production. On the other hand, while a higher surface area should be able to produce more distilled water, the developed $\Delta T$ will be less, airflow will decrease, and thus the electric energy produced from the turbine will decrease. 
Previous studies have shown that the temperature profile observed and the corresponding airflow at a given radius can be correlated with the power production from the SCPP. Kiwan and Salam [19] reported an increase in the power production curves by increasing the chimney radius to $350 \mathrm{~m}$. Although a larger radius slightly improves the produced power, there is a limitation in the chimney radius above which the construction cost contradicts the benefits in power production. This trend can be aimed at the excessive heat loss at a high radius from both the collector and ground to the soil. Thus, there will be an upper limit for the airflow temperature in the collector in terms of the equilibrium between heat loss and inlet solar radiation. The present study suggests a chimney radius in the range of 5 to $25 \mathrm{~m}$ to be optimum for maximum power output and lower fixed capital costs. Toghraie et al. [50] showed that although the output power of the solar chimney increased by increasing the radius, the efficiency decreased significantly. The pressure gradient created by the increase in the chimney radius, which increases the airflow rate, is the main explanation for the increase in power output. However, at a high radius, the heat transfer area increased at constant heat flux, resulting in a significant decrease in the efficiency.

The obtained trends suggest that there is an optimum production of distilled water and electric energy while keeping the construction cost of the HSCPP reasonable. A pool radius of $15 \mathrm{~m}$ was previously determined to be the optimum choice, allowing for a chimney inlet air temperature of $63^{\circ} \mathrm{C}$, while also not hurting the efficiency of the power plant in substantial ways. The obtained results show that the pool radius and the air temperature are strongly inversely proportional, conforming to the phenomenon described earlier. It should be noted that the HSCCP can be operated as a CT at night and as an SCPP during the day, offering 24-h energy production. The SCPP mode produces an annual electrical power of $380,263.1 \mathrm{kWh}$ and 139,443.4 tons of distilled water. The produced electrical energy is comparable to the value of $377,000 \mathrm{kWh} /$ year reported by Zuo et al. [47]. However, the present structure reported 1.5-fold higher water desalination production ( 92,616 tons/year). Sangi et al. [39] illustrated that by decreasing the radius of the seawater pool, the air velocity profile through the collector increased dramatically at the chimney base. The same study reported that the air velocity increased at a constant radius with rising solar radiation. An accelerated natural air draught tower is created by the temperature gradient between the inside and outside of the chimney.

\subsection{CT Performance}

Figure 6a shows the minimum, maximum, and average monthly electric power generation from the operation of the HSCCP in the CT mode. The maximum and average power outputs follow the same trends, which is different than the minimum values. It was observed that the energy production starts around mid-February and increases to reach the highest values during the hot months (May to September) and then decreases to reach less than $250 \mathrm{kWh}$ in November-December. For the minimum production, a sudden decrease in the power production rate was observed in July and August. The observed trend can be attributed to the impact of the ambient temperature on the system performance. The operation of the HSCPP as CT depends on two main principles: mass transfer when droplets of water evaporate and extract the required latent heat from the water pool, leading to the cooling effect; and heat transfer, where the developed $\Delta T$ determines the magnitude of the pressure difference and the airflow to operate the turbine and produce electricity. In the low-temperature months (January, February, November, and December), the temperature difference between the water droplets and inlet air is low, creating a small $\Delta T$ and resulting in very low power production. On the other hand, a high-temperature month will create high $\Delta T$ and enhance both the mass and heat transfer, resulting in significant cooling and airflow and thus high energy production. The average power produced from the CT operation was $1700 \mathrm{kWh}$, with a maximum of $2300 \mathrm{kWh}$ reported in August. It is known that the $\mathrm{RH}$ and the temperature are the main climate parameters that have a strong impact on the output power from CT. Figure $6 \mathrm{~b}$ presents the output energy in correlation 
with temperature and $\mathrm{RH}$. It is expected that increasing the temperature will increase the gradient driving force of the inside air movement and this will increase the power output. However, it can be seen in Figure $6 \mathrm{~b}$ that the variation in temperature during the operation as CT is negligible and cannot be considered as a dominant factor in this case. Instead, the $\mathrm{RH}$ is inversely proportional to the CT output power, and its obvious fluctuations deem it to be the main driving force behind the change in electricity production. During the early period of the day (00:00 am-05:00 am), the RH sees a noticeable increase from 57\% to $63 \%$, followed by a drop to an even lower value than it initially started at, and the opposite of this trend applies to the output power, where it decreases slightly from 173 to $170 \mathrm{~kW}$ and then increases back to $171 \mathrm{~kW}$. The effect of RH on the power productivity is felt even more strongly after 17:00 when the humidity shoots up to the maximum value of $67 \%$, and the output power declines from 176 to $170 \mathrm{~kW}$ along with it. The effect of humidity on the performance of the CT is explained by the change in water evaporation, since highly saturated (humid) air can only accept a small amount of extra water molecules from the sprinklers, which leads to less cooling by the evaporation of the water into the air, and this leads to a smaller temperature gradient, hence less air movement inside the chimney. Fujita et al. investigated the effect of $\mathrm{RH}$ on the heat transfer between air and an evaporating water droplet and concluded that low RH decreases the droplet temperature, and high humidity increases its temperature [51]. Additionally, Ruberto et al. [52] investigated the evaporation rate of supercooled water droplets at varying values of $\mathrm{RH}$ and constant temperature, and they found that the evaporation rate was strongly linearly and inversely proportional to the $\mathrm{RH}$, with a decrease in the evaporation rate from about 340 to $170 \mu \mathrm{m}^{2} / \mathrm{s}$ when the humidity increased from 20 to $60 \%$.

As discussed earlier, the outside temperature is a critical factor that decides power productivity in the tower, and this is further demonstrated by Figure $6 c$, in which the outside temperature and outlet temperature seem to have a constant temperature difference of approximately $6{ }^{\circ} \mathrm{C}$, where the latter one is cooler due to the vaporization of water leading to the subsequent downward movement. Because the outside temperature in the early morning period seems almost constant (and with it, the outlet temperature), the air velocity inside the chimney does not change much during the period and stays at the value of $25.2 \mathrm{~m} / \mathrm{s}$. However, after 17:00, the outside air temperature dwindles from 36.5 to $34{ }^{\circ} \mathrm{C}$, and with it, the air velocity drops from 25.4 to $25.2 \mathrm{~m} / \mathrm{s}$, further demonstrating the effect the outside temperature has on the downward movement in the tower. The CT mode produces a total annual electrical power of $252,862.8 \mathrm{kWh}$, a significant increase that makes up $66.5 \%$ of the HSCPP mode, highlighting the feasibility of the hybrid design. The influence of the $\Delta T$ between the air inside and outside the chimney is connected to this observed trend. The differential pressure increases by raising the $\Delta T$, leading to an increase in the velocity of the air within the chimney and providing more dynamic power to drive the turbine and improve the output power. In the same way, the amount of water that can be evaporated to achieve the necessary cooling effect decreases as the percent $\mathrm{RH}$ of the external air increases, contributing to lower power generation. The pattern observed also highlights the effect of the wind speed and its hydrodynamics on system efficiency. The change in the kinetic energy of the air within the chimney can be increased by any potential changes in the direction and speed of the wind and thus the power output can be enhanced. Sakonidou et al. [53] illustrated that the air velocity profile within the chimney exhibits a non-interacting boundary layer with local maxima at the center. The high air velocity evolved due to the high-pressure difference between the inside and the ambient air temperature. Arce et al. [54] confirmed that the thermal gradients between the absorber plate and the air adjacent to it affect the airflow rate through the SC. The same work emphasized the significance of the upper side of the chimney's wind velocity in generating a draft to increase the velocity of the airflow. 
(a)

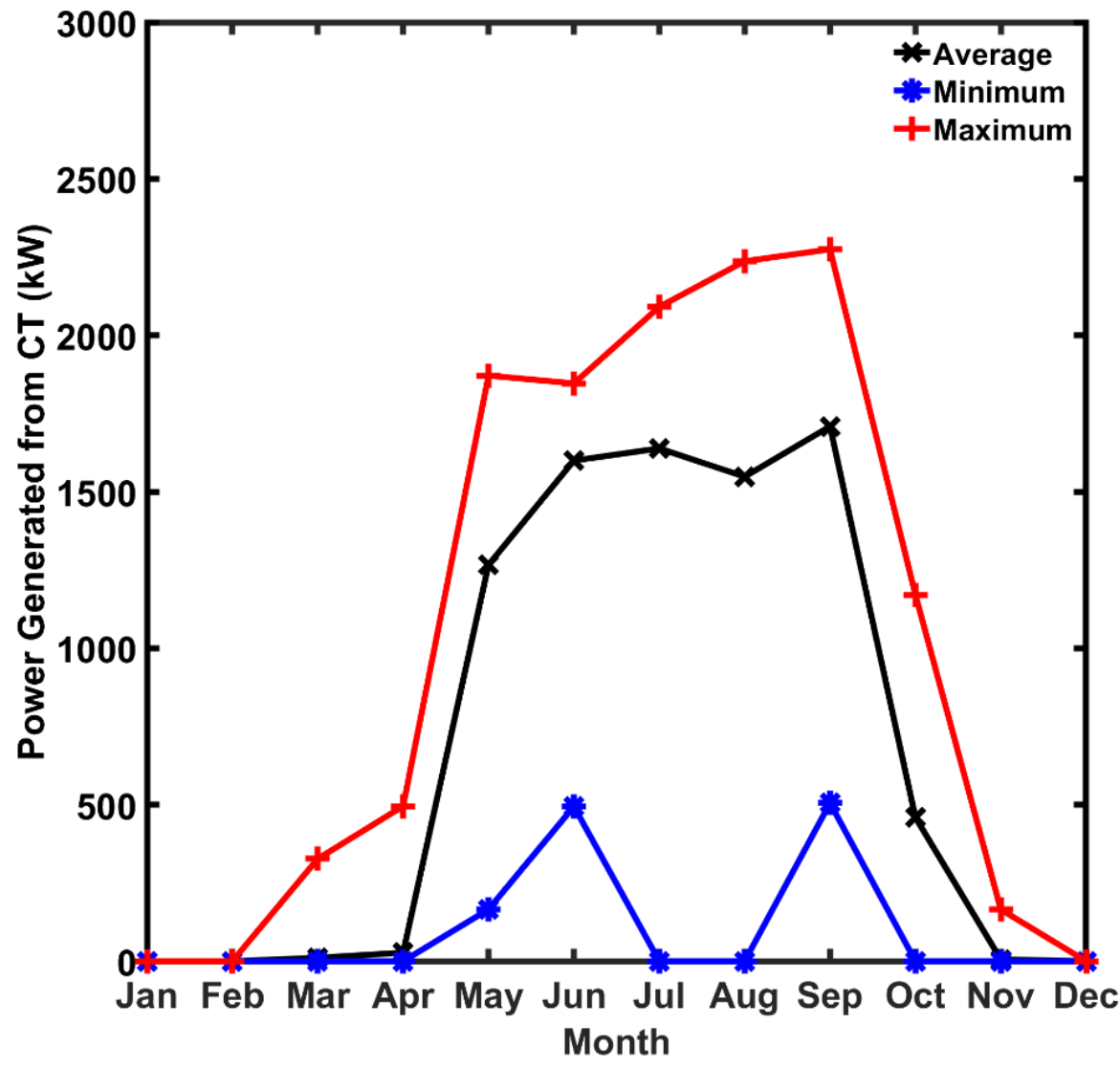

(b)

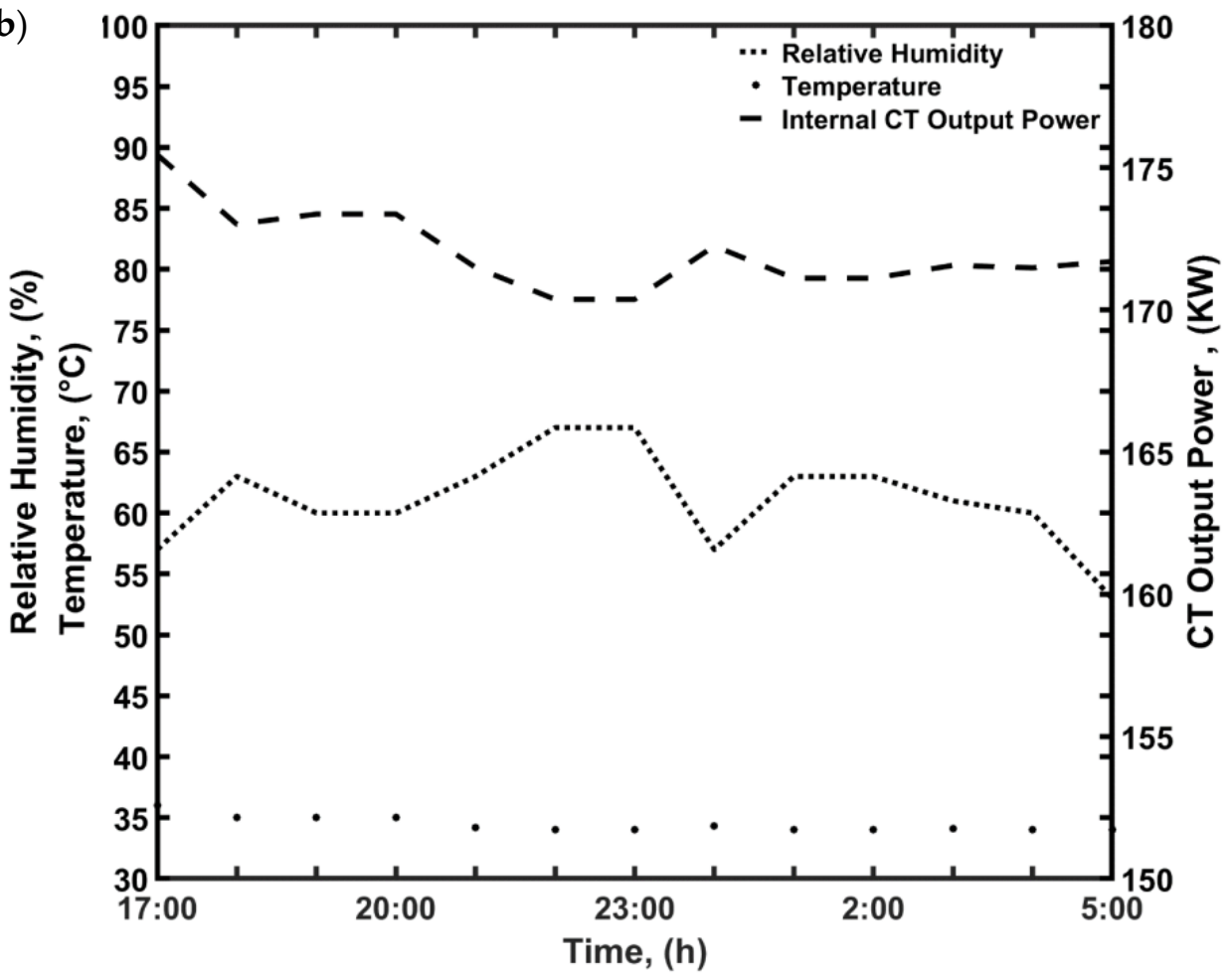


(c)

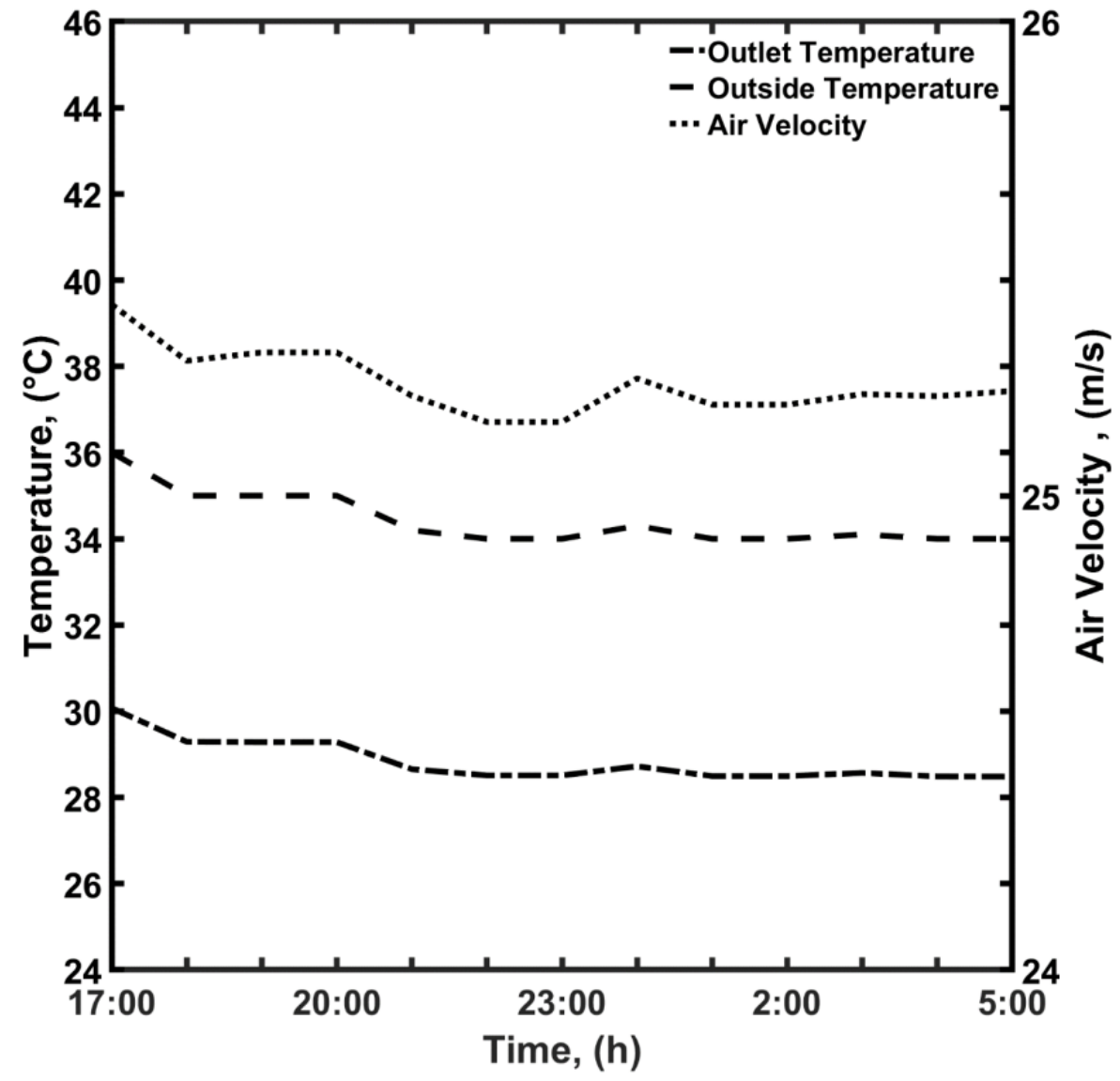

Figure 6. (a) Monthly electric power generation from the CT mode, (b) the effect of the RH and temperature on the output power from $\mathrm{CT}$, and (c) the effect of the outside temperature on the air velocity within the $\mathrm{CT}$.

\subsection{HSCPP Performance}

The proposed HSCPP model was devised, and its performance regarding distilled water and electric power production is summarized in Figure 7a,b, respectively. The plant produces up to $170 \mathrm{~kW}$ during the early morning and night periods, and up to $148 \mathrm{~kW}$ during the day, showing the benefit of adding the CT to the conventional SCPP design and its feasibility for electricity production. Meanwhile, distilled water production goes up to 56 tons at 14:00, further adding to the plant's value. Since the air temperature gradient, and thus the electric power and distilled water production, is a strong function of the solar radiation intensity, it is well within expectation for these three variables to follow a similar trend in the SCPP mode. Furthermore, the graphs show that a setup that maximizes power production could be installed, such that the cooler periods where the solar irradiance is minimal are utilized to maintain power production by normally having the HSCPP operating as an SCPP during the high irradiance periods, and a CT between sunset and sunrise. One possible modification of the design could be optimizing the operating hours for the two modes, and this is because as the figures show, the solar irradiance is relatively low in the beginning and end of the SCPP 5:00-17:00 period, which leads to the question of whether or not the extension of the CT mode operating hours at those low-irradiance times would be a net positive overall, but this would need further studying of the plant performance under different time distributions for the two modes. Table 6 summarizes a full year of a working plant, producing electric power and distilled water, and a comparison between the conventional SCPP and the proposed HSCPP is presented. For both power plants (conventional and hybrid), the production is at its lowest value during the winter months (at the beginning and end of the year) due to low radiation and high humidity, 
while the summer months witness an increased outside temperature, solar irradiance, and lower humidity, giving rise to the plant's most productive period. The electricity production by the HSCPP over the span of one year is $633,125.9 \mathrm{kWh}$, which is $66.5 \%$ higher than that produced by the conventional SCPP $(380,263.1 \mathrm{kWh})$, while the production rate of distilled water reaches $139,443.4$ tons, which is almost double the amount produced from a conventional SCPP.

(a)

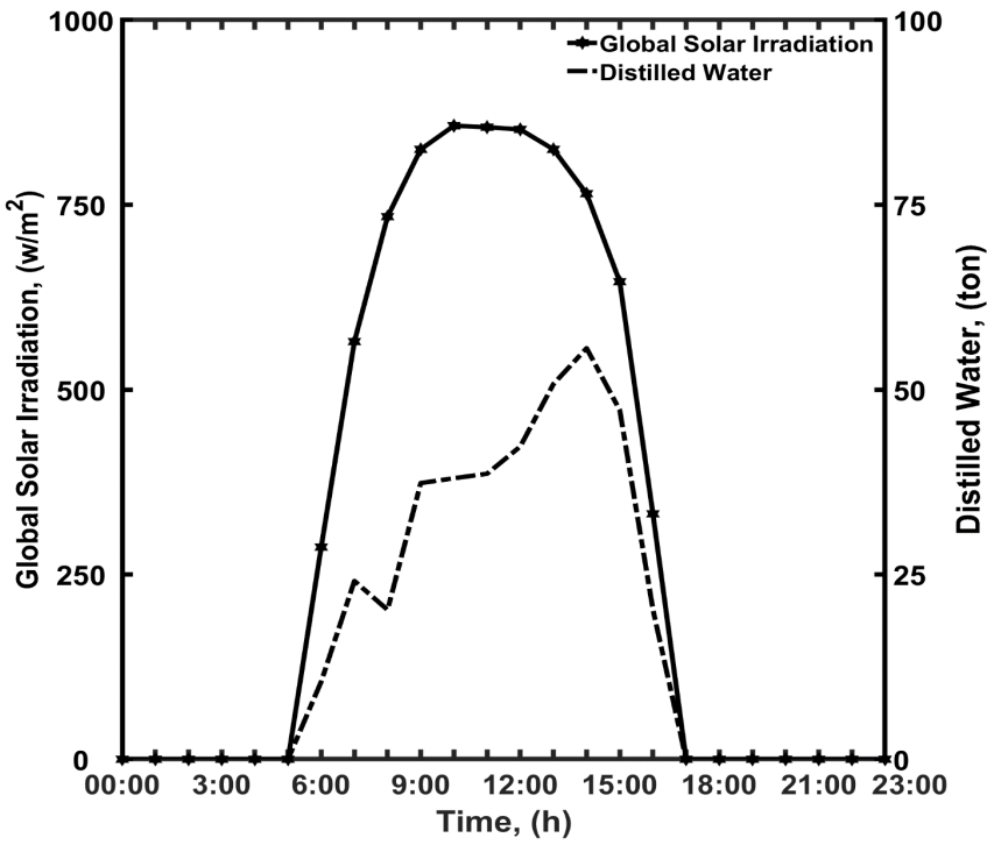

(b)

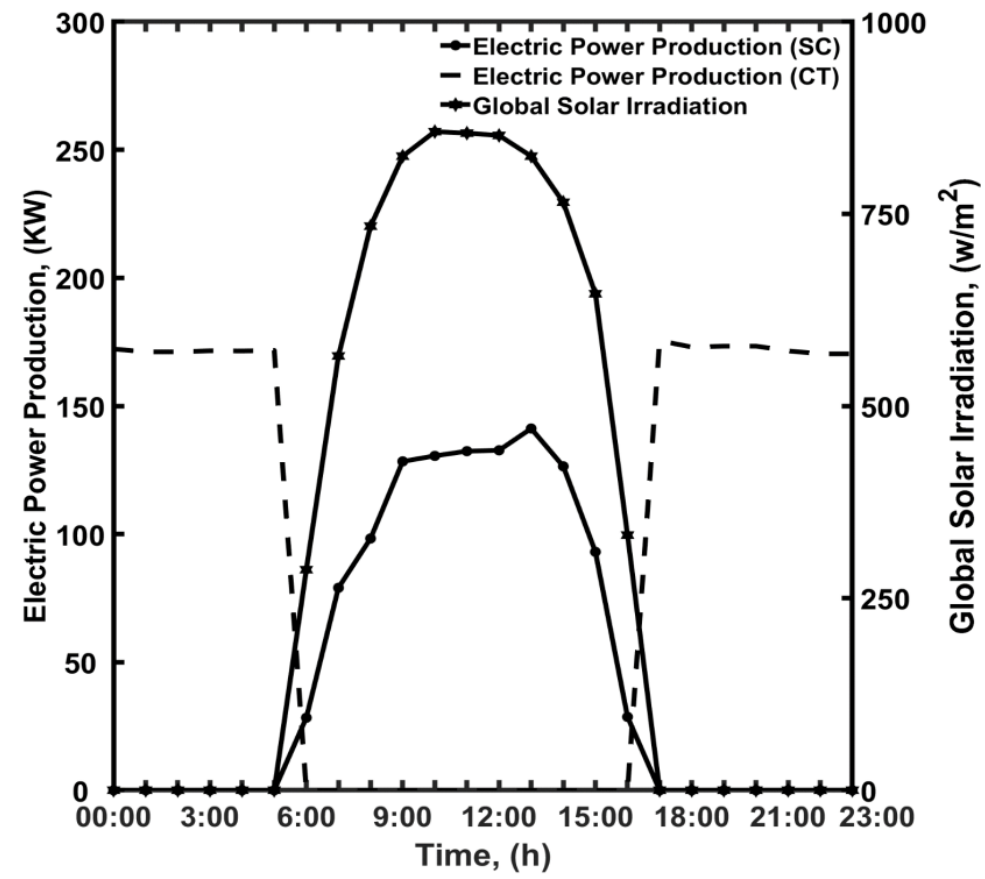

Figure 7. The energy and distilled water production from HSCPP (a) distilled water and (b) electric power production. 
Table 6. Monthly electrical power production and distilled water generation from the HSCPP.

\begin{tabular}{|c|c|c|c|c|c|}
\hline Month & $\begin{array}{l}\text { Monthly } \\
\text { Global Solar } \\
\text { Irradiation } \\
\left(\mathbf{k W h} / \mathbf{m}^{2}\right)\end{array}$ & $\begin{array}{c}\text { Electric } \\
\text { Energy, } \\
\text { SCPP (kWh) }\end{array}$ & $\begin{array}{c}\text { Electric } \\
\text { Energy, CT } \\
\text { (kWh) }\end{array}$ & $\begin{array}{c}\text { Electric } \\
\text { Energy, } \\
\text { HSCPP } \\
\text { (kWh) SCPP } \\
\text { \& CT }\end{array}$ & $\begin{array}{c}\text { Distilled } \\
\text { Water (ton) }\end{array}$ \\
\hline January & 185.944 & $29,515.89$ & 0 & $29,515.89$ & 8960.995 \\
\hline February & 175.847 & $28,347.98$ & 0 & $28,347.98$ & $10,243.77$ \\
\hline March & 204.597 & $32,542.67$ & 327.133 & $32,869.8$ & $11,499.31$ \\
\hline April & 206.499 & $32,119.36$ & 824.2792 & $32,943.64$ & $13,501.25$ \\
\hline May & 234.531 & $35,510.46$ & $39,262.42$ & $74,772.87$ & $13,339.45$ \\
\hline June & 231.652 & $34,419.29$ & $47,988.49$ & $82,407.78$ & $14,510.86$ \\
\hline July & 231.961 & $34,129.4$ & $50,792.73$ & $84,922.13$ & $14,816.74$ \\
\hline August & 226.995 & $34,068.48$ & $47,993.29$ & $82,061.77$ & $13,176.88$ \\
\hline September & 212.239 & $31,472.88$ & $51,265.52$ & $82,738.4$ & $11,412.38$ \\
\hline October & 206.029 & $30,662.84$ & $14,243.77$ & $44,906.61$ & 9558.005 \\
\hline November & 189.334 & $29,553.07$ & 165.1956 & $29,718.26$ & 9339.416 \\
\hline December & 173.411 & $27,920.79$ & 0 & $27,920.79$ & 9084.36 \\
\hline Total & 2479.04 & $380,263.1$ & $252,862.8$ & $633,125.9$ & $139,443.4$ \\
\hline
\end{tabular}

\subsection{Environmental Impact Assessment}

Table 7 presents the annual electrical power and freshwater production from the SCPP and HSCPP in addition to the annual reduction in the $\mathrm{CO}_{2}$ emissions with the same amount of energy and water produced from natural gas (NG) burning. Operating the SCPP in the hybrid mode exhibited an increase in the electrical power and freshwater production 1.67- and 1.54-fold higher than the classical solar chimney. Besides, the annual reduction in the $\mathrm{CO}_{2}$ emissions with this amount of electricity and water produced from NG burning was estimated to be 617.7 metric tons/year, which will contribute to a decrease in Qatar's GHG emissions. The $\mathrm{CO}_{2}$ emissions in Qatar from fossil fuel burning and industrial activities have increased massively since 1970, recording up to 106.5 million metric tons in 2019, with an annual increase of 1.85 million metric tons/year. Compared to other energy sources, such as coal-fired power plants, the HSCPP is a pollution-free facility. The benefits offered from the present system would produce sustainable and renewable clean energy and water while contributing to a reduction in the country's $\mathrm{CO}_{2}$ emissions.

Table 7. Comparison of the performance of the HSCPP against a conventional SCPP.

\begin{tabular}{ccc}
\hline Item & SCPP [48] & HSCPP \\
\hline Electrical power production, (kWh/year) & 380,263 & 633,125 \\
Fresh water production (metric tons/year) & 90,000 & 139,443 \\
$\mathrm{CO}_{2}$ emission reduction (tons/year) & 294.4 & 617.5 \\
\hline
\end{tabular}

In addition to the $\mathrm{CO}_{2}$ emissions, the biggest problem with flue gas from powerplant and desalination processes is the emission of other gases, such as $\mathrm{NO}_{\mathrm{x}}, \mathrm{SO}_{\mathrm{x}}$, and $\mathrm{H}_{2} \mathrm{~S}$, which have a dramatic impact on the environment. The proposed HSCPP is expected to reduce the emissions of these gases by $20 \%, 15 \%$, and $13 \%$, respectively. NOx can cause asthma, inflammation of the lungs, and bronchitis at the human level, and lowers the ozone layer, inducing skin cancer that triggers ultra-violet rays from the Sun at the environmental level. Further, NOx can react with humidity to produce $\mathrm{HNO}_{2}$ and $\mathrm{HNO}_{3}$ and destroy green living on Earth. $\mathrm{SO}_{\mathrm{x}}$ can be converted to $\mathrm{H}_{2} \mathrm{SO}_{4}$, generating the same drastic results on all living species, such as the corroding of structures, substance, or clothing degradation. $\mathrm{H}_{2} \mathrm{~S}$ is a toxic gas that can cause serious problems for humans and properties. The reduction in these gasses in addition to free energy production is an addition to the benefits of the proposed design. 


\subsection{Economic Analysis}

The cost of the proposed HSCPP design considering the chimney, glass base, concert basin, turbine, and installation cost was estimated to be US $\$ 3.25$ million. The estimated cost is in good agreement with the cost estimated by Abdelsalam et al. [35] for a low electrical capacity of $481 \mathrm{MW}$. However, it slightly differs from the costs proposed by Al-Dabbas [55] and Dehghani and Mohammadi [56] due to the differences in capacity, components, and labor costs. The individual component cost was determined using the exponent method as per Equation (14) as reported by Gavin and Towler [57]. The estimated cost also included the integration of the cooling section

$$
\text { Cost }=\text { Tabulated Factor }+(\text { Component Size })^{(\text {Exponent factor/size })}
$$

The proposed design peculiarity maximizes energy output while lowering initial costs and providing an environmentally friendly design that is simple to deconstruct and reinstall. The HSCPP has the ability to produce electricity for $24 \mathrm{~h}$ and operate as a cooling tower during the night. The cost of cooling is correlated to the price of electricity per $1{ }^{\circ} \mathrm{C}$ By contrast, the proposed design could achieve the required cooling free of charge. From this perspective, the HSCPP will always be economically viable and has a cost advantage. Considering the ability of the HSCPP to produce electricity and water, and to work as a CT, the overall cash flow analysis showed a payback time of 4.5 years, ROI of $27.8 \%$, and DCFRR of $25.6 \%$. The obtained short payback time and the high ROI and DCFRR highlight the economic benefits observed from the proposed HSCPP. The short payback time, which represents the cost of the investment divided by the annual cash flow, confirms the desirable aspect of the investment. The positive values of ROI and DCFRR encourage and support investment effectiveness compared to the cost of the investment.

\section{Conclusions}

A performance study of HSCPP in Doha, Qatar was presented. It was shown that the HSCPP can run as an SCPP during the daytime and as a CT during the nighttime. The results showed that the HSCPP can run continuously if the weather conditions are favorable. The proposed HSCPP exhibited an electrical power and freshwater production 1.67- and 1.54-fold higher than the classical solar chimney, which can reduce the annual $\mathrm{CO}_{2}, \mathrm{NO}_{x}, \mathrm{SO}_{x}$, and $\mathrm{H}_{2} \mathrm{~S}$ emissions by $5 \% 20 \%, 15 \%$, and $13 \%$, respectively. The annual electricity production from the HSCPP was observed to be $633,125.9 \mathrm{kWh}$, which is $66.5 \%$ higher than that produced by the conventional SCPP $(380,263.1 \mathrm{kWh})$. There is a strong seasonal difference in power production, with the HSCPP's output improving throughout the summer. Increasing the solar irradiations and reducing heat transfer resulted in an increase in the air mass flow rate and consequently increased the power generation from the HSCPP. Abundant solar radiation and high amounts of solar irradiation in the vast desert land mean it is a suitable site for the construction of HSCPP to utilize local solar irradiation. The results also showed that the HSCPP outperformed the traditional SCPP two to one in the amount of electricity and freshwater generated, as well as the amount of $\mathrm{CO}_{2}$ reduction. The results showed that the HSCPP would be a feasible solution to provide electricity and fresh water in Qatar. Future work may include studying interfacing the HSCPP to a traditional water desalination power plant to take advantage of excess hot air produced by the desalination plant to improve the performance of the HSCPP. Overall, the study revealed that HSCPP could be employed to improve energy access in rural areas with a high return on investment (payback period of 4.5 years, ROI of $27.8 \%$, and DCFRR of $25.6 \%$ ). Future work on the social and environmental impact of such projects through surveys and dialogues with the stakeholders is highly recommended.

Supplementary Materials: Detailed equations of the mathematical model for the HSCPP are available online at https:/ / www.mdpi.com/article/10.3390/su132112100/s1. 
Author Contributions: Conceptualization, E.A. (Emad Abdelsalam), F.K., F.A.; methodology, E.A. (Emad Abdelsalam), F.K., D.H. and A.K.; validation, E.A. (Emad Abdelsalam), F.K., M.A. and F.A.; formal analysis, E.A. (Eyad Almaitta), F.K., F.A. and M.A.; investigation, E.A. (Eyad Almaitta), F.K., A.K. and A.O.; writing-original draft preparation, A.O, E.A. (Eyad Almaitta), F.K., M.A., F.A. and M.T.; writing-review and editing, A.O., F.K., M.A., F.A. and M.T.; visualization, D.H., A.K. and D.H.; supervision E.A. (Eyad Almaitta), and F.K. All authors have read and agreed to the published version of the manuscript.

Funding: This research received no external funding.

Data Availability Statement: Not available.

Acknowledgments: The authors would like to the thank the MERG lab for their support in developing this work. Special thanks to Luz Gonzalez for proofreading.

Conflicts of Interest: The authors declare no conflict of interest.

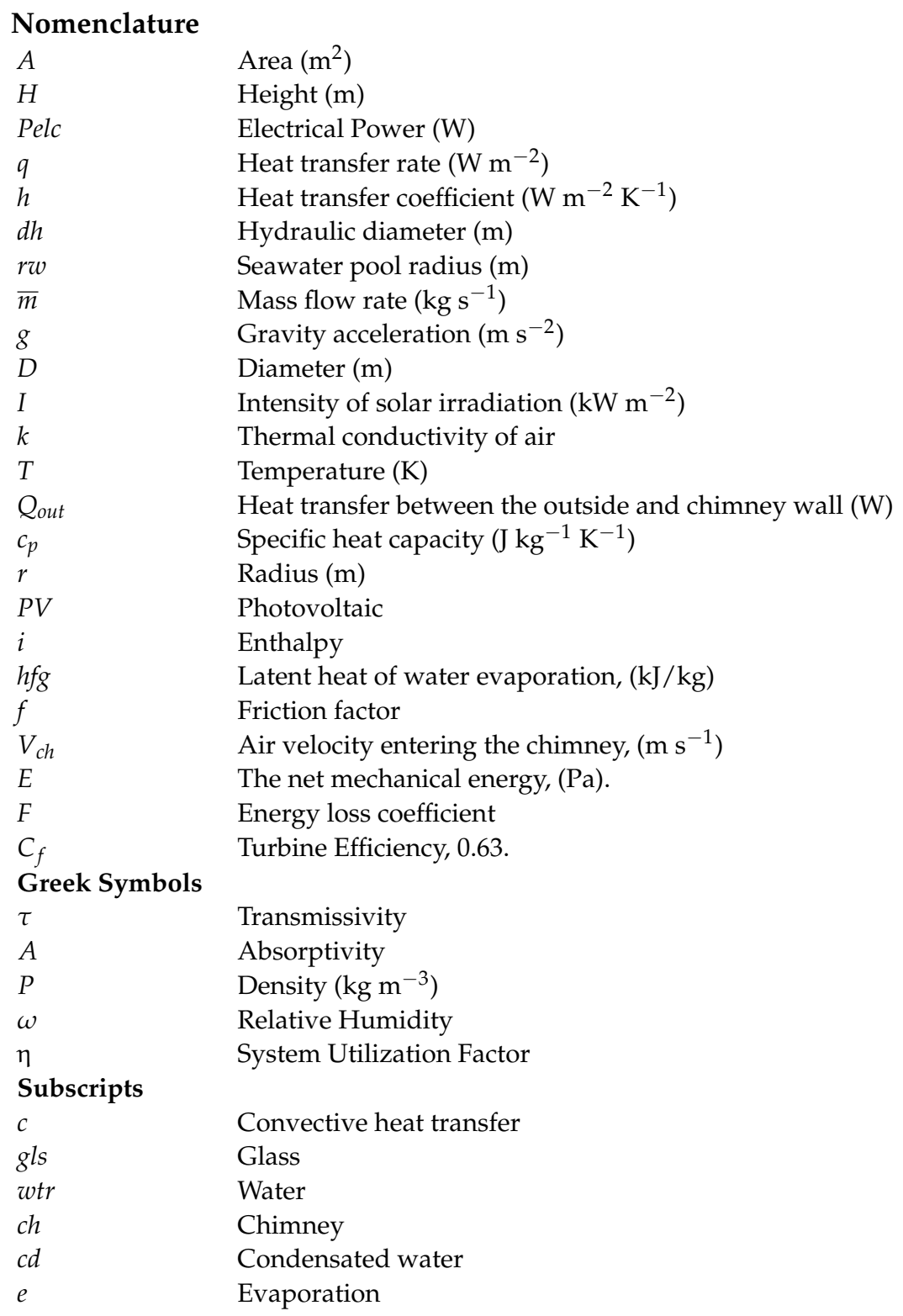




$\begin{array}{ll}\text { col } & \text { Collector } \\ \text { ent } & \text { Entrance } \\ \text { out } & \text { Outside } \\ r & \text { Radiative heat transfer } \\ \text { sky } & \text { Sky } \\ \text { abs } & \text { Absorber } \\ \text { air } & \text { Airflow } \\ \text { vap } & \text { The humid air resulting from spraying water on the dry air in the case of CT } \\ \text { Net } & \text { Net }\end{array}$

\section{References}

1. Mohsin, M.; Abbas, Q.; Zhang, J.; Ikram, M.; Iqbal, N. Integrated effect of energy consumption, economic development, and population growth on $\mathrm{CO}_{2}$ based environmental degradation: A case of transport sector. Environ. Sci. Pollut. Res. 2019, 26, 32824-32835. [CrossRef]

2. Takalkar, G.D.; Bhosale, R.R.; Kumar, A.; Almomani, F.; Khraisheh, M.A.M.; Shakoor, R.A.; Gupta, R.B. Transition metal doped ceria for solar thermochemical fuel production. Sol. Energy 2018, 172, 204-211. [CrossRef]

3. International Energy Agency. Energy, Water \& the Sustainability Development Goals, Excerpt from World Energy Outlook 2018. 2018, pp. 1-15. Available online: https://webstore.iea.org/download/direct/2459 (accessed on 12 August 2021).

4. Franzluebbers, A.J. Cattle Grazing Effects on the Environment: Greenhouse Gas Emissions and Carbon Footprint. In Management Strategies for Sustainable Cattle Production in Southern Pastures; Elsevier: Amsterdam, The Netherlands, 2020; pp. 11-34.

5. Almomani, F.; Judd, S.; Bhosale, R.R.; Shurair, M.; Aljaml, K.; Khraisheh, M. Intergraded wastewater treatment and carbon bio-fixation from flue gases using Spirulina platensis and mixed algal culture. Process Saf Environ Prot. 2019, 124, 240. [CrossRef]

6. Zhou, X.; Wang, F.; Ochieng, R.M. A review of solar chimney power technology. Renew. Sustain. Energy Rev. 2010, 14, 2315-2338. [CrossRef]

7. Dhahri, A.; Omri, A. A review of solar chimney power generation technology. Int. J. Eng. Adv. Technol. 2013, 2, 1-17.

8. Kasaeian, A.; Ghalamchi, M.; Ahmadi, M.H.; Ghalamchi, M. GMDH algorithm for modeling the outlet temperatures of a solar chimney based on the ambient temperature. Mech. Ind. 2017, 18, 216. [CrossRef]

9. Ming, T.; Liu, W.; Xu, G. Analytical and numerical investigation of the solar chimney power plant systems. Int. J. Energy Res. 2006, 30, 861-873. [CrossRef]

10. Schlaich, J. The solar chimney: Electricity from the Sun, Edition Axel Menges; Scientific Research: Stuttgart, Germany, 1995.

11. Ghalamchi, M.; Kasaeian, A.; Ahmadi, M.H.; Ghalamchi, M. Evolving ICA and HGAPSO algorithms for prediction of outlet temperatures of constructed solar chimney. Int. J. Low-Carbon Technol. 2017, 12, 84-95. [CrossRef]

12. Schlaich, J.; Bergermann, R.; Schiel, W.; Weinrebe, G. Sustainable electricity generation with solar updraft towers. Structural Eng. Int. J. Int. Assoc. Bridge Struct. Eng. 2004, 14, 225-229. [CrossRef]

13. Tingzhen, M.; Wei, L.; Guoling, X.; Yanbin, X.; Xuhu, G.; Yuan, P. Numerical simulation of the solar chimney power plant systems coupled with turbine. Renew. Energy 2008, 33, 897-905. [CrossRef]

14. Zou, Z.; He, S. Modeling and characteristics analysis of hybrid cooling-tower-solar-chimney system. Energy Convers. Manag. 2015, 95, 59-68. [CrossRef]

15. Xu, Y.; Zhou, X. Performance of a modified solar chimney power plant for power generation and vegetation. Energy 2019, 171, 502-509. [CrossRef]

16. Asayesh, M.; Kasaeian, A.; Ataei, A. Optimization of a combined solar chimney for desalination and power generation. Energy Convers. Manag. 2017, 150, 72-80. [CrossRef]

17. Khan, M.A.M.; Rehman, S.; Al-sulaiman, F.A. A hybrid renewable energy system as a potential energy source for water desalination using reverse osmosis: A review. Renew. Sustain. Energy Rev. 2018, 97, 456-477. [CrossRef]

18. Niroomand, N.; Amidpour, M. New combination of solar chimney for power generation and seawater desalination. Desalin. Water Treat. 2013, 51, 7401-7411. [CrossRef]

19. Kiwan, S.; Salam, Q.I.A. Solar chimney power-water distillation plant (SCPWDP). Desalination 2018, 445, 105-114. [CrossRef]

20. Ming, T.; de Richter, R.K.; Meng, F.; Pan, Y.; Liu, W. Chimney shape numerical study for solar chimney power generating systems. Int. J. Energy Res. 2013, 37, 310-322. [CrossRef]

21. Chergui, T.; Larbi, S.; Bouhdjar, A. Thermo-hydrodynamic aspect analysis of flows in solar chimney power plants-A case study. Renew. Sustain. Energy Rev. 2010, 14, 1410-1418. [CrossRef]

22. Pasumarthi, N.; Sherif, S.A. Experimental and theoretical performance of a demonstration solar chimney model-part I: Mathematical model development. Int. J. Energy Res. 1998, 22, 277-288. [CrossRef]

23. Zuo, L.; Ding, L.; Chen, J.; Zhou, X.; Xu, B.; Liu, Z. Comprehensive study of wind supercharged solar chimney power plant combined with seawater desalination. Sol. Energy 2018, 166, 59-70. [CrossRef]

24. Cao, F.; Ma, Q.; Zhao, L.; Guo, L. Design and simulation of a novel geothermalsolar combined chimney power plant. In Proceedings of the 26th International Conference on Efficiency, Cost, Optimization, Simulation and Environmental Impact of Energy Systems (ECOS 2013), Guilin, China, 15-19 July 2013; Volume 84, pp. 186-195. 
25. Chergui, T.; Larbi, S.; Bouhdjar, A. Modelling and simulation of solar chimney power plant performances in southern region of Algeria. In Proceedings of the 2011 Fourth International Conference on Modeling, Simulation and Applied Optimization, Kuala Lumpur, Malaysia, 19-21 April 2011. [CrossRef]

26. Kiwan, S.; Al-Nimr, M.; Salim, I. A hybrid solar chimney/photovoltaic thermal system for direct electric power production and water distillation. Sustain. Energy Technol. Assess. 2020, 38, 100680. [CrossRef]

27. Okoye, C.O.; Atikol, U. A parametric study on the feasibility of solar chimney power plants in North Cyprus conditions. Energy Convers. Manag. 2014, 80, 178-187. [CrossRef]

28. Mathur, J.; Mathur, S.; Anupma. Summer-performance of inclined roof solar chimney for natural ventilation. Energy Build. 2006, 38, 1156-1163. [CrossRef]

29. Fluri, T.P.; von Backström, T.W. Performance analysis of the power conversion unit of a solar chimney power plant. Sol. Energy 2008, 82, 999-1008. [CrossRef]

30. Miqdam, T.C.; Hussein, A.K. Basement kind effects on air temperature of a solar chimney in Baghdad-Iraq weather. Int. J. Appl. Sci. 2011, 2, 12-20. [CrossRef]

31. Tingzhen, M.; Wei, L.; Yuan, P. Numerical Analysis of the Solar Chimney Power Plant with Energy Storage Layer. In ISES Solar World Congress 2007, ISES 2007; Springer: Berlin/Heidelberg, Germany, 2007; Volume 3, pp. 1800-1805. [CrossRef]

32. Zuo, L.; Yuan, Y.; Li, Z.; Zheng, Y. Experimental research on solar chimneys integrated with seawater desalination under practical weather condition. Desalination 2012, 298, 22-33. [CrossRef]

33. Tavakolinia, F. Wind-Chimney: Integrating the Principles of a Wind-Catcher and a Solar-Chimney to Provide Natural Ventilation. Master's Thesis, California Polytechnic State University, San Luis Obispo, CA, USA, 2011; p. 48. Available online: http:/ / digitalcommons.calpoly.edu/theses / 678 (accessed on 18 June 2021).

34. Zandian, A.; Ashjaee, M. The thermal efficiency improvement of a steam Rankine cycle by innovative design of a hybrid cooling tower and a solar chimney concept. Renew. Energy 2013, 51, 465-473. [CrossRef]

35. Abdelsalam, E.; Kafiah, F.M.; Tawalbeh, M.; Almomani, F.; Azzam, A.R.; Alzoubi, I.; Alkasrawi, M. Performance analysis of hybrid solar chimney-power plant for power production and seawater desalination: A sustainable approach. Int. J. Energy Res. 2020, 45, 17327-17341. [CrossRef]

36. Abdelmohimen, M.A.H.; Algarni, S.A. Numerical investigation of solar chimney power plants performance for Saudi Arabia weather conditions. Sustain. Cities Soc. 2018, 38, 1-8. [CrossRef]

37. Okoye, C.O.; Taylan, O. Performance analysis of a solar chimney power plant for rural areas in Nigeria. Renew. Energy 2017, 104, 96-108. [CrossRef]

38. El-Haroun, A.A. Performance Evaluation of Solar Chimney Power Plants in Egypt. 2012. Available online: www.ijopaasat.in (accessed on 26 November 2020).

39. Sangi, R. Performance evaluation of solar chimney power plants in Iran. Renew. Sustain. Energy Rev. 2012, 16, 704-710. [CrossRef]

40. Hamdan, M.O. Analysis of a solar chimney power plant in the Arabian Gulf region. Renew. Energy 2011, 36, 2593-2598. [CrossRef]

41. Larbi, S.; Bouhdjar, A.; Chergui, T. Performance analysis of a solar chimney power plant in the southwestern region of Algeria. Renew. Sustain. Energy Rev. 2010, 14, 470-477. [CrossRef]

42. Nizetic, S.; Ninic, N.; Klarin, B. Analysis and feasibility of implementing solar chimney power plants in the Mediterranean region. Energy 2008, 33, 1680-1690. [CrossRef]

43. Guo, P.; Li, J.; Wang, Y. Annual performance analysis of the solar chimney power plant in Sinkiang, China. Energy Convers. Manag. 2014, 87, 392-399. [CrossRef]

44. Ahmed, M.R.; Patel, S.K. Computational and experimental studies on solar chimney power plants for power generation in Pacific Island countries. Energy Convers. Manag. 2017, 149, 61-78. [CrossRef]

45. Akhtar, Z.; Rao, K.V.S. Study of economic viability of $200 \mathrm{MW}$ solar chimney power plant in Rajasthan, India. In Proceedings of the 2014 1st International Conference on non Conventional Energy (ICONCE 2014), Kalyani, India, 16-17 January 2014; pp. 84-88.

46. Abdelsalam, E.; Kafiah, F.; Alkasrawi, M.; Al-Hinti, I.; Azzam, A. Economic Study of Solar Chimney Power-Water Distillation Plant (SCPWDP). Energies 2020, 13, 2789. [CrossRef]

47. Zuo, L.; Zheng, Y.; Li, Z.; Sha, Y. Solar chimneys integrated with sea water desalination. Desalination 2011, 276, 207-213. [CrossRef]

48. Larbi, S.; Bouhdjar, A.; Meliani, K.; Taghourt, A.; Semai, H. Solar chimney power plant with heat storage system performance analysis in South Region of Algeria. In Proceedings of the 2015 3rd International Renewable and Sustainable Energy Conference (IRSEC), Marrakech, Morocco, 10-13 December 2015; pp. 1-6.

49. Asnaghi, A.; Ladjevardi, S.M. Solar chimney power plant performance in Iran. Renew. Sustain. Energy Rev. 2012, 16, 3383-3390. [CrossRef]

50. Toghraie, D.; Karami, A.; Afrand, M.; Karimipour, A. Effects of geometric parameters on the performance of solar chimney power plants. Energy 2018, 162, 1052-1061. [CrossRef]

51. Fujita, A.; Kurose, R.; Komori, S. Experimental study on effect of relative humidity on heat transfer of an evaporating water droplet in air flow. Int. J. Multiph. Flow 2010, 36, 244-247. [CrossRef]

52. Ruberto, S.; Reutzsch, J.; Weigand, B. Experimental investigation of the evaporation rate of supercooled water droplets at constant temperature and varying relative humidity. Int. Commun. Heat Mass Transf. 2016, 77, 190-194. [CrossRef]

53. Sakonidou, E.P.; Karapantsios, T.D.; Balouktsisa, A.I.; Chassapisa, D. Modeling of the optimum tilt of a solar chimney for maximum air flow. Solar Energy 2008, 82, 80-94. [CrossRef] 
54. Arcea, J.; Jiménez, M.J.; Guzmán, J.D.; Heras, M.R.; Alvarez, G.; Xamán, J. Experimental study for natural ventilation on a solar chimney. Renewable Energy 2009, 34, 2928-2934. [CrossRef]

55. Al-Dabbas, M.A. A performance analysis of solar chimney thermal power systems. Therm. Sci. 2011, 15, 619-642. [CrossRef]

56. Dehghani, S.; Mohammadi, A.H. Optimum dimension of geometric parameters of solar chimney power plants-A multi-objective optimization approach. Sol. Energy 2014, 105, 603-612. [CrossRef]

57. Towler, G.; Sinnott, R. Chemical Engineering Design: Principles, Practice and Economics of Plant and Process Design; Elsevier: Amsterdam, The Netherlands, 2012. 